\title{
Activation of Nrf2-mediated anti-oxidant genes by antrodin C prevents hyperglycemia-induced senescence and apoptosis in human endothelial cells
}

\author{
Kumar K.J. Senthil ${ }^{1}$, Vani M. Gokila ${ }^{1,2}$ and Sheng-Yang Wang ${ }^{1,2,3}$ \\ 1 Department of Forestry, National Chung Hsing University, Taichung, Taiwan \\ 2 National Chung Hsing University/University of California at Davis, Plant and Food Biotechnology Center, National Chung \\ Hsing University, Taichung, Taiwan \\ ${ }^{3}$ Agricultural Biotechnology Research Center, Academia Sinica, Taipei, Taiwan \\ Correspondence to: Sheng-Yang Wang, email: taiwanfir@dragon.nchu.edu.tw
}

Keywords: antrodin C, Antrodia cinnamomea, high glucose, endothelial cells, senescence, Gerotarget

Received: June 21, $2017 \quad$ Accepted: July 25, $2017 \quad$ Published: August 04, 2017

Copyright: Senthil et al. This is an open-access article distributed under the terms of the Creative Commons Attribution License 3.0 (CC BY 3.0), which permits unrestricted use, distribution, and reproduction in any medium, provided the original author and source are credited.

\section{ABSTRACT}

In the present study, we investigated the effects of antrodin C (ADC), a maleimide derivative isolated from mycelia of Antrodia cinnamomea, on high glucose (HG, 30 $\mathrm{mM}$ )-accelerated endothelial dysfunction in vitro. HG-induced cytotoxicity in human umbilical vein endothelial cells (HUVECs) was significantly ameliorated by ADC. In addition, treatment with ADC significantly prevented HG-induced senescence, growth arrest at the $G_{1}-S$ transition phase and apoptosis in HUVECs. Moreover, the increased level of intracellular reactive oxygen species (ROS) under HG condition was significantly ameliorated by ADC. Further analysis revealed that ADC-mediated antioxidant effects were due to up-regulation of cellular anti-oxidant genes, such as HO-1 and NQO-1 via promotion of the transcriptional activity of Nrf2, which was further confirmed by the failure of ADC to protect HUVECs from HG-induced dysfunction under HO-1 inhibition or Nrf2 silencing. Furthermore, hyperosmotic glucose (HOG, $60 \mathrm{mM}$ )induced uncontrolled production of ROS, rapid apoptotic cell death and HUVEC injury were significantly prevented by ADC, whereas these preventive effects were barely observed in HO-1 inhibited or Nrf2 silenced cells. Taken together, these results suggest that ADC may represent a promising intervention in diabetic-associated cardiovascular diseases by activating the Nrf2-dependent cellular anti-oxidant defense system.

\section{INTRODUCTION}

Hyperglycemia, a characteristic feature of diabetes mellitus (DM) and metabolic syndrome has emerged as a major health problem that rapidly causes vascular and organ dysfunction [1]. It has been estimated that by 2030 , developing countries in Asia and the Middle East will have the largest increases in the prevalence of type-2 DM due to modernization of lifestyles and nutrition [2]. Common complications of diabetes mellitus include age-associated diseases, such as vascular ageing, hypertension and atherosclerosis [3]. Vascular endothelial cells are highly specialized and active cells that regulate thrombosis and inflammatory processes. Thus, alterations in endothelial cells and the vasculature play a critical role in the pathogenesis of a broad spectrum of the most serious human diseases [4]. Vascular endothelial cell senescence, which is highly associated with diabetes mellitus [5], promotes vascular dysfunction and is accompanied by increased vascular risk [6].

Vascular senescence can be induced by a plethora of internal or external insults, including telomere dysfunction [7], ionizing radiation [8], reactive oxygen species (ROS) [9], inflammatory cytokines [10,11], drugs [12] and high glucose $[13,14]$. Increasing evidence indicates that high glucose, a characteristic feature of diabetes mellitus, induces oxidative stress, which invokes irreversible growth arrest in vitro within a few days, a term referred to 
as stress-induced premature senescence [15]. It has been established that hyperglycemia-induced cell-cycle arrest in endothelial cells is mediated by $\mathrm{p} 21^{\mathrm{CIP} 1}$ and $\mathrm{p} 16^{\mathrm{INK} 4 \mathrm{~A}}$, two cyclin-dependent kinase inhibitors (CDKs) [16]. In addition, previous studies have demonstrated that exposure of vascular endothelial cells to high glucose causes a significant increase in apoptosis, possibly associated with an increase in intracellular ROS, alteration in fattyacid metabolism, impaired Akt activation by insulin and increased caspase- 3 activity $[17,18]$. In the pathological state, oxidative stress results in excessive production of ROS. ROS, include free radicals such as superoxide and hydroxyl radicals, and non-radical species (hydrogen peroxide). Excessive ROS generation overwhelms endogenous antioxidant systems, and overproduction of ROS also reduces the efficacy of endogenous antioxidants. Under such conditions, induction of antioxidants by external factors plays a critical role in cellular stress response [19, 20].

Eukaryotic cells have a primary and secondary defense mechanism to respond to oxidative stresses. In particular, phase I enzymes such as cytochrome p450 and phase II enzymes, including heme oxygenase-1 (HO1), NAD(P) H:quinone oxidoreductase 1 (NQO1) and glutathione- $S$-transferase (GST) are rapidly activated by an endogenous mechanism through which oxidative toxicants are removed before they can damage the DNA [21]. Transcriptional activation of antioxidants or detoxifying genes are predominantly regulated by a redoxsensitive transcription factor nuclear factor erythroid 2-related factor-2 (Nrf2) [22]. Dietary phytochemicals are identified as potent activators of cellular antioxidant genes through the induction of the Nrf2 signaling pathway thereby bolstering the anti-oxidant defense system in a variety of cells.

Antrodia cinnamomea (Syn. Antrodia camphorate or Taiwanofungus camphoratus) is a unique medicinal mushroom that has long been used as a Chinese folk medicine in Taiwan for the treatment of various human illnesses including, liver diseases, food and drug intoxication, diarrhea, abdominal pain, hypertension, allergies, skin and tumorigenic diseases [23-25]. Recent scientific investigations have revealed that $A$. cinnamomea has extensive pharmacological effects including anticancer, anti-inflammation, anti-oxidant, anti-microbial, anti-diabetic, anti-hypertensive, anti-hyperlipidemia, antimetastasis, immunomodulatory, hepatoprotective and neuroprotective effects [23-25]. The therapeutic efficacy of this mushroom may be due its high phytocompound content which includes terpenoids, polysaccharides, benzenoids, lignans, nucleic acid, benzoquinone derivatives, steroids, and maleic/succinic acid derivatives. In addition, $A$. cinnamonea is one of the richest sources of biologically active compounds such as antcins, anticinates, antrodins and antroquinonls [25].

$$
\text { Initially, Nakamura et al. [26] isolated }
$$

5 new maleic and succinic acid derivatives from the mycelia of $A$. cinnamomea, and among them, the maleimide derivatives antrodin $\mathrm{B}(\mathrm{ADB})$ and antrodin C (ADC) exhibited anti-cancer properties in Lewis lung carcinoma cells in vitro. Subsequent studies also demonstrated that the pyrrolidione ADC strongly inhibited the lipopolysaccharide (LPS)-induced production of proinflammatory cytokines and chemokines in macrophage cells $[27,28]$. Recently, we reported that ADC possesses anti-metastatic effects in human breast cancer cells through the inhibition of epithelial-to-mesenchymal transition and tumor cell migration in vitro [29]. However, other biological effects of this pharmacologically important compound are largely unknown. In this study, the protective effects of ADC on hyperglycemia-induced vascular endothelial cell senescence and apoptosis were examined. The anti-oxidant potential of ADC was compared with the known anti-oxidant resveratrol.

\section{RESULTS}

\section{Cytotoxic effects of ADC on HUVECs}

First, the cytotoxicity of ADC was determined. HUVECs were incubated with increasing doses of ADC $(1,5,10,20$ and $40 \mu \mathrm{M})$ for 24,48 and $72 \mathrm{~h}$, and cell viability was determined by MTT colorimetric assay. Dose-response results showed that ADC does not affect cell viability up to the concentration of $10 \mu \mathrm{M}$ for $72 \mathrm{~h}$ (Figure 1B). Concentrations greater than $10 \mu \mathrm{M}$ showed a significant reduction in cell viability after $24 \mathrm{~h}$, a similar trend was also observed at 48 and $72 \mathrm{~h}$ (Figure 1B). Based on these results, we chose a non-cytotoxic concentration of ADC $(10 \mu \mathrm{M})$ as the treatment dose for further experiments. HUVECs exposed to $\mathrm{HG}(15,30$ and $60 \mathrm{mM}$ ) for 24-72 h exhibited a dose- and time-dependent reduction in cell viability. Particularly, treatment with 30 and $60 \mathrm{mM}$ for $72 \mathrm{~h}$ reduced cell number to $49.3 \%$ and $11 \%$, respectively compared to control NG $(5.5 \mathrm{mM})$ cells (Figure 1C). Next, we examined the protective effects of ADC on HG-induced reduction in cell viability. Treatment with ADC $(10 \mu \mathrm{M})$ significantly reversed the effects of HG in HUVECs. Indeed, compared with HG-only treated cells, the cell viability was markedly increased to 2-fold by co-treatment with ADC for 24-72 h (Figure 1D).

\section{ADC prevents HG-induced apoptosis in HUVECs}

Results of flow cytometric analysis showed that exposure of HUVECs to HG (30 mM) for $72 \mathrm{~h}$ resulted in a moderate increase in cell apoptosis, whereas treatment with ADC $(10 \mu \mathrm{M})$ or RES $(5 \mu \mathrm{M})$ failed to induce HUVEV apoptosis (Figure 2A). A non-cytotoxic concentration of ADC $(10 \mu \mathrm{M})$ significantly prevented 
HG-mediated apoptosis, which was significantly reduced to $2.7 \% \pm 0.7 \%$ from $17.6 \% \pm 1 \%(P<0.05$, vs. $\mathrm{HG}$ alone). In addition, HUVECs incubated with NG (5.5 $\mathrm{mM})$ exhibited a basal level of apoptosis $(2.6 \% \pm 0.4 \%)$, whereas treatment with ADC $(10 \mu \mathrm{M})$ or $\operatorname{RES}(5 \mu \mathrm{M})$ even blocked the basal level of apoptosis. The percentage of apoptosis was noted as $1 \% \pm 0.1 \%$ and $0.8 \% \pm$ $0.05 \%$, respectively (Figure $2 \mathrm{~A}$ ). In contrast, exposure of HUVECs to HG for $72 \mathrm{~h}$ did not increase LDH level in the culture media suggesting that $\mathrm{HG}$ did not cause HUVEC injury or necrosis (Figure 2B). To further clarify the effect of ADC on HG-induced apoptosis, caspase signaling cascade proteins were examined by western blot analysis. As shown in Figure 2C, HG induced loss of mitochondrial membrane potential as evidenced by the increase in cytochrome C protein level (7.09-fold) in the cytoplasm. Apparently, ADC significantly altered the mitochondrial membrane potential as indicated by the decrease in cytochrome $\mathrm{C}$ expression to 3.44-fold in HGinduced HUVECs. In addition, HG resulted in significant activation of caspase-9 (2.6-fold) and caspase-3 (3.1-fold) compared to the NG-treated cells, indicating the treatment

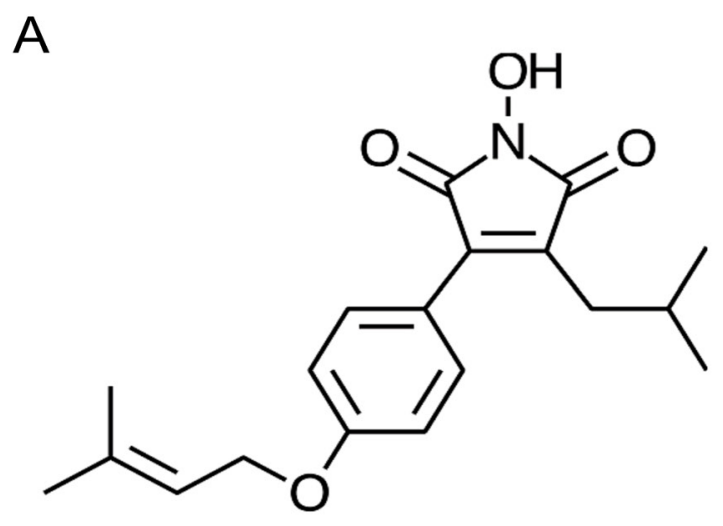

C
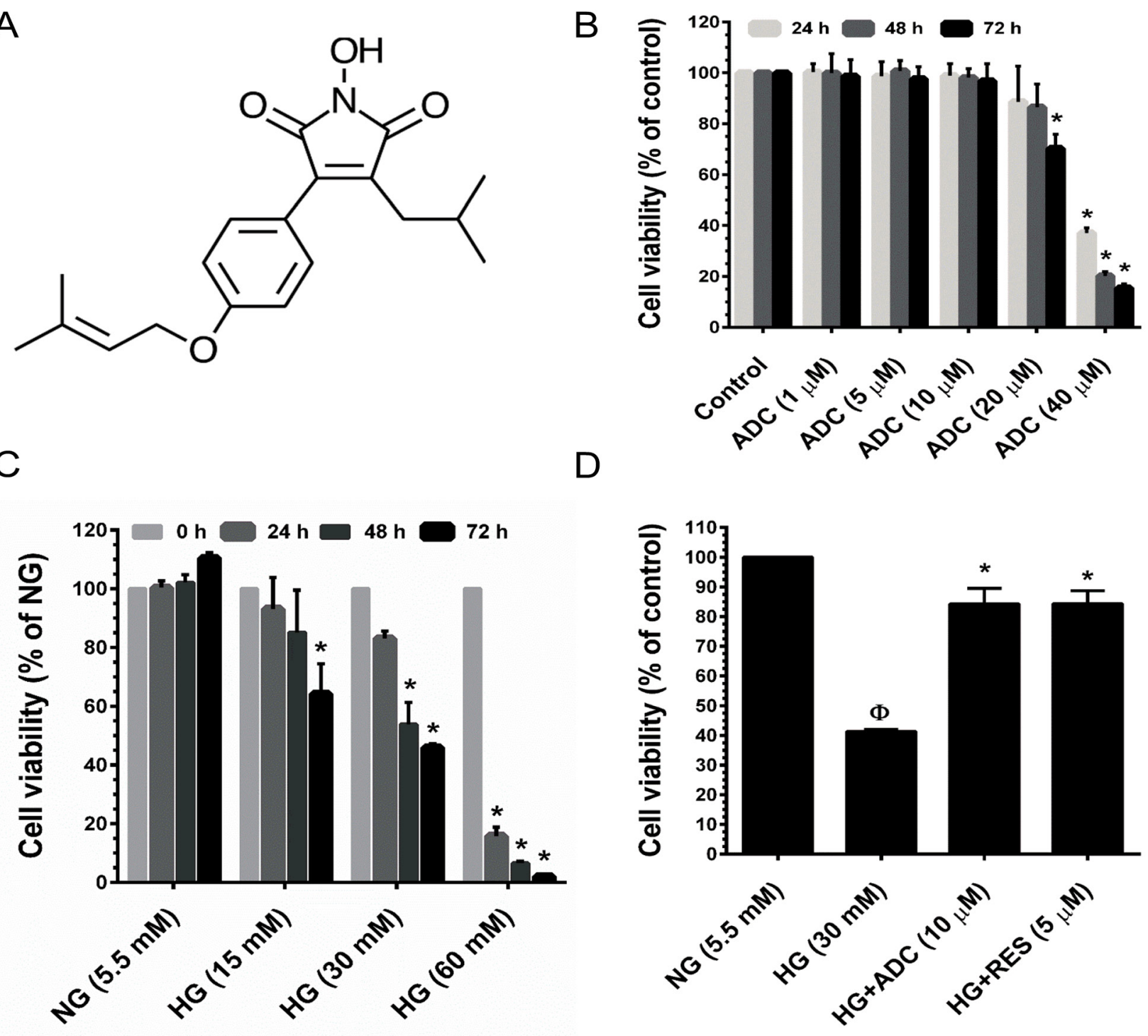

Figure 1: Cytotoxic effect of HG and ADC on HUVECs. A. Chemical structure of Antrodin C (ADC). B. HUVECs were incubated with increasing concentrations of ADC for 24-72 $\mathrm{h}$ and the cell viability was measured by MTT assay. The percentage of cell viability was compared with the control (0.01\% DMSO) group. C. HUVECs were incubated with various doses of HG for 24-72 h and cell viability was measured by MTT assay. The percentage of cell viability was compared with the NG treatment group. D. Cells were incubated with HG in the presence or absence of ADC or RES for $72 \mathrm{~h}$. The percentage of cell viability was compared with the NG treatment group. Values represent the mean $\pm \mathrm{SD}$ of three independent experiments. Statistical significance was set at ${ }^{\Phi} P<0.05$ compared to NG $v s$. HG and $* P<$ 0.05 compared to HG vs. samples. 
of HUVECs with HG induced apoptotic cell death. However, caspase-9 and caspase-3 expression levels in
HG-induced HUVECs were attenuated to 1.48-fold and 0.88-fold, respectively (Figure 2D, 2E).
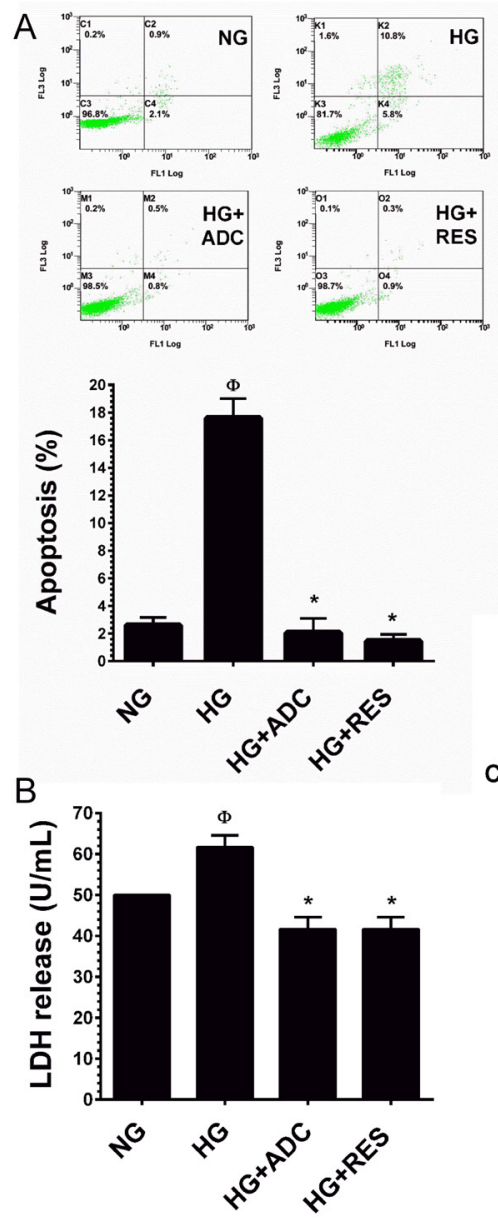

Cytochrome C
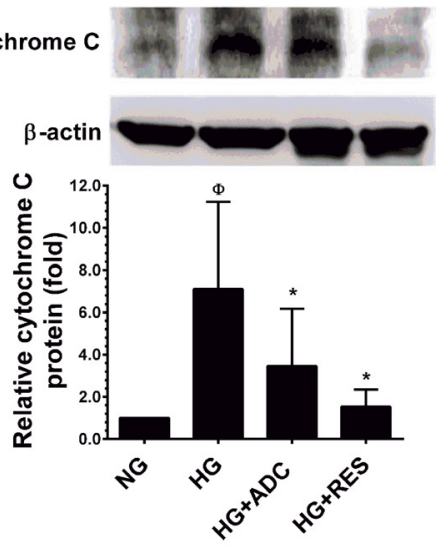

E

Caspase-3 Clev-caspase-3

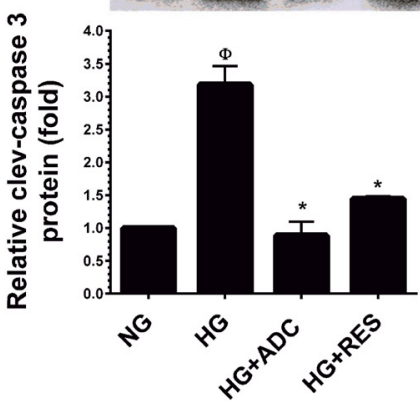

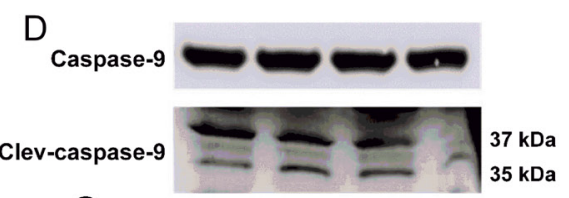
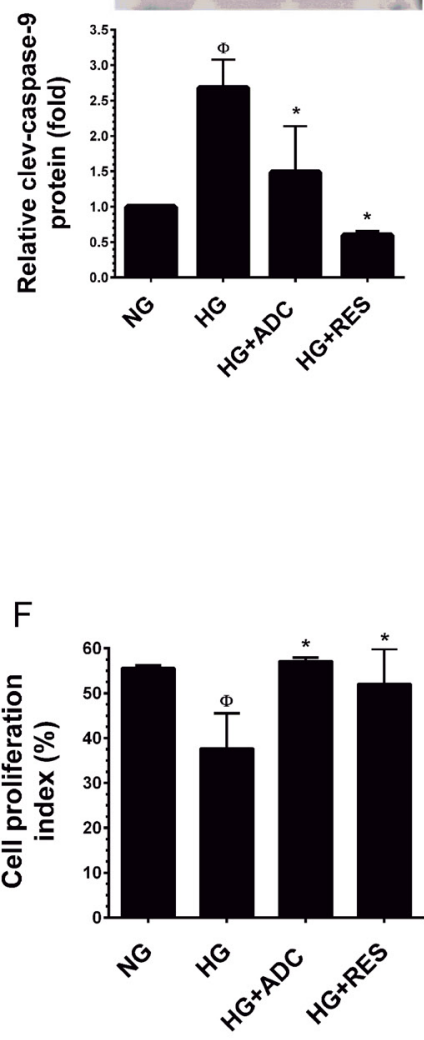

G
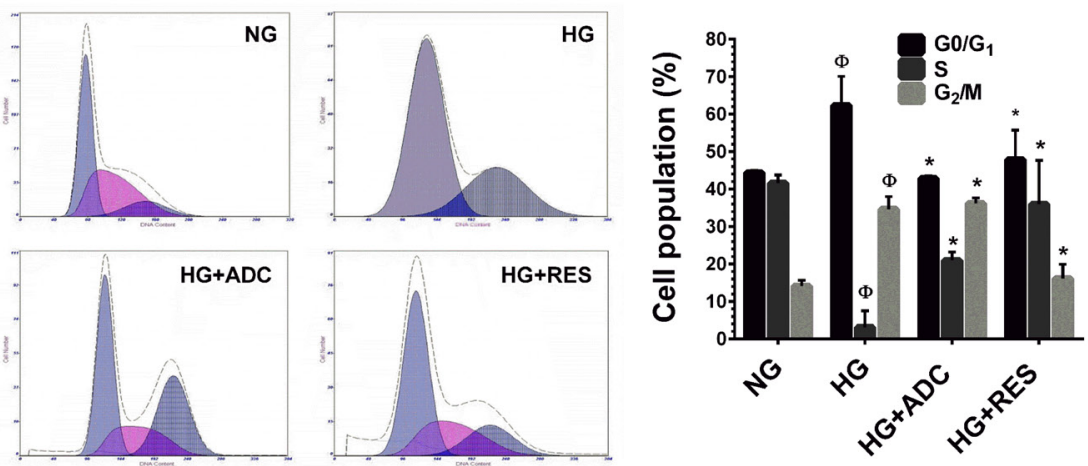

Figure 2: Protective effect of ADC on HG-induced HUVEC apoptosis and growth arrest. A. HUVECs were incubated with HG in the presence or absence of ADC or RES for $72 \mathrm{~h}$. Apoptotic cell death was performed with Annexin V/PI staining and the hypodiploid DNA was determined by flow cytometry. B. HUVECs were treated with HG in the presence or absence of ADC or RES for $72 \mathrm{~h}$. LDH release in the supernatant of HUVEC cultures was measured by LDH assay kit as described in Materials and Methods. C.-E. Protein expression levels of cytochrome C, caspase- 9 and caspase-3 levels were determined by western blot analysis. The relative protein expression of cytochrome $\mathrm{C}$ was normalized with $\beta$-actin, whereas cleaved capase- 9 and cleaved caspase- 3 levels were normalized with pro-caspase-9 and pro-caspase-3, respectively. F. HUVECs proliferation index was determined by flow cytometry. G. HUVECs were incubated with HG in the presence of ADC or RES for $72 \mathrm{~h}$. Cell-cycle distribution was measured by flow cytometer using PI. Percentage of cell population in each transition phase is shown in the histogram. Values represent the mean $\pm \mathrm{SD}$ of three independent experiments. Statistical significance was set at ${ }^{\oplus} P<0.05$ compared to NG $v$. HG and $* P<0.05$ compared to HG $v s$. samples. 


\section{ADC prevents HG-induced growth arrest in HUVECs}

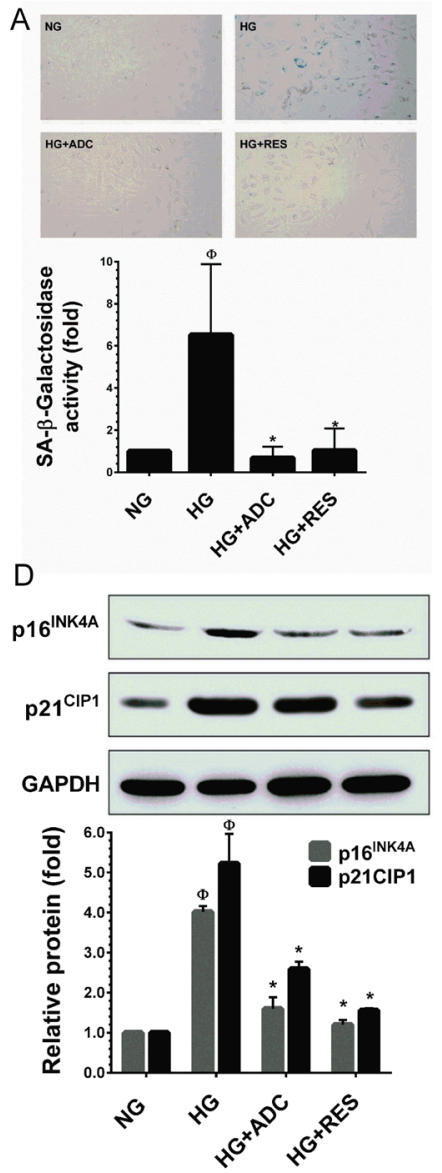

Next, to examine whether the reduction in cell number was associated with growth arrest, the effects

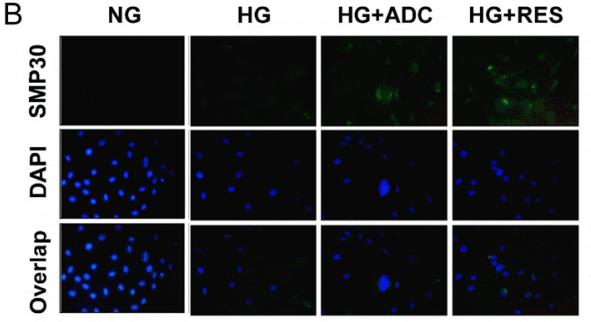

E
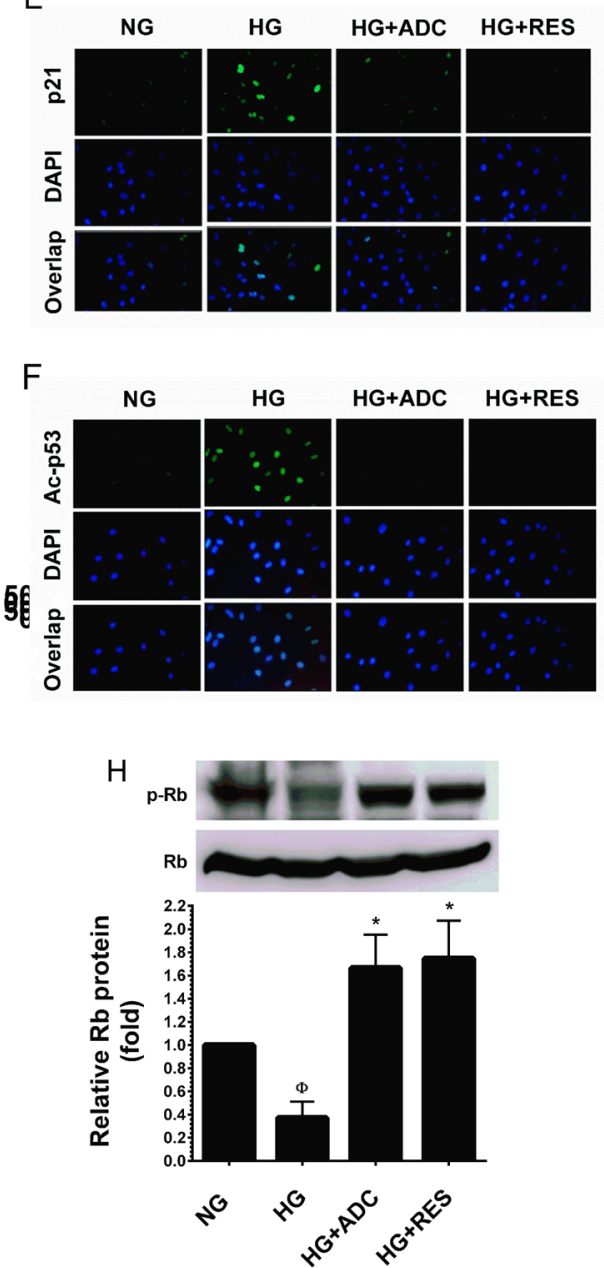

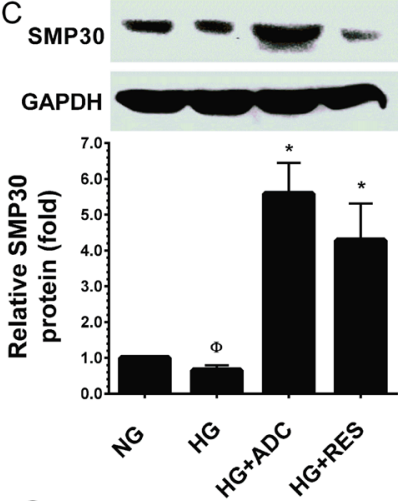

G
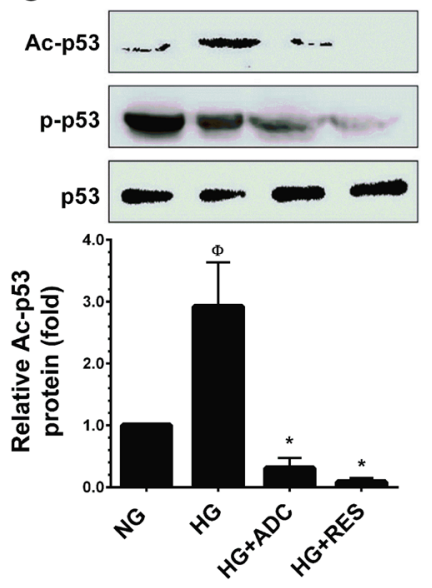

Figure 3: ADC prevents HG-induced senescence in HUVECs. To determine the effect of ADC on HG-induced senescence, HUVECs were incubated with HG in the presence or absence of ADC or RES for $72 \mathrm{~h}$. A. Cellular senescence was determined by SA$\beta$-gal assay. The top panel shows representative figures and the lower panel shows quantitative analysis of SA- $\beta$-gal positive cells per microscopic field. B.,E.,F. The protein expression of SMP30, p2 $1^{\mathrm{CIP} 1}$ and acetylated p53 was measured by immunofluroscence using specific primary antibodies and FITC-conjugated secondary antibody (green). The cellular localization of SMP30, p21 $1^{\mathrm{CIP} 1}$ and acetylated p53 was photographed using a fluorescence microscope. DAPI was used to stain the nucleus. C. SMP30 protein expression level was determined by western blot analysis and the relative SMP30 expression was normalized with GAPDH. D. Senescence-associated protein $\mathrm{p} 21^{\mathrm{CIP} 1}$ and $\mathrm{p} 16^{\mathrm{INK} 4 \mathrm{~A}}$ levels were determined by western blotting and the relative protein levels were normalized with GAPDH. G.,H. The protein levels of acetylated p53, phosphorylated p53 and phosphorylated Rb levels were measured by western blot analysis. The relative protein levels of ac-p53 and p-Rb were normalized with total p53 and total Rb levels, respectively. Values represent the mean $\pm \mathrm{SD}$ of three independent experiments. Statistical significance was set at ${ }^{\Phi} P<0.05$ compared to NG $v s$. HG and $* P<0.05$ compared to HG $v s$. samples. 

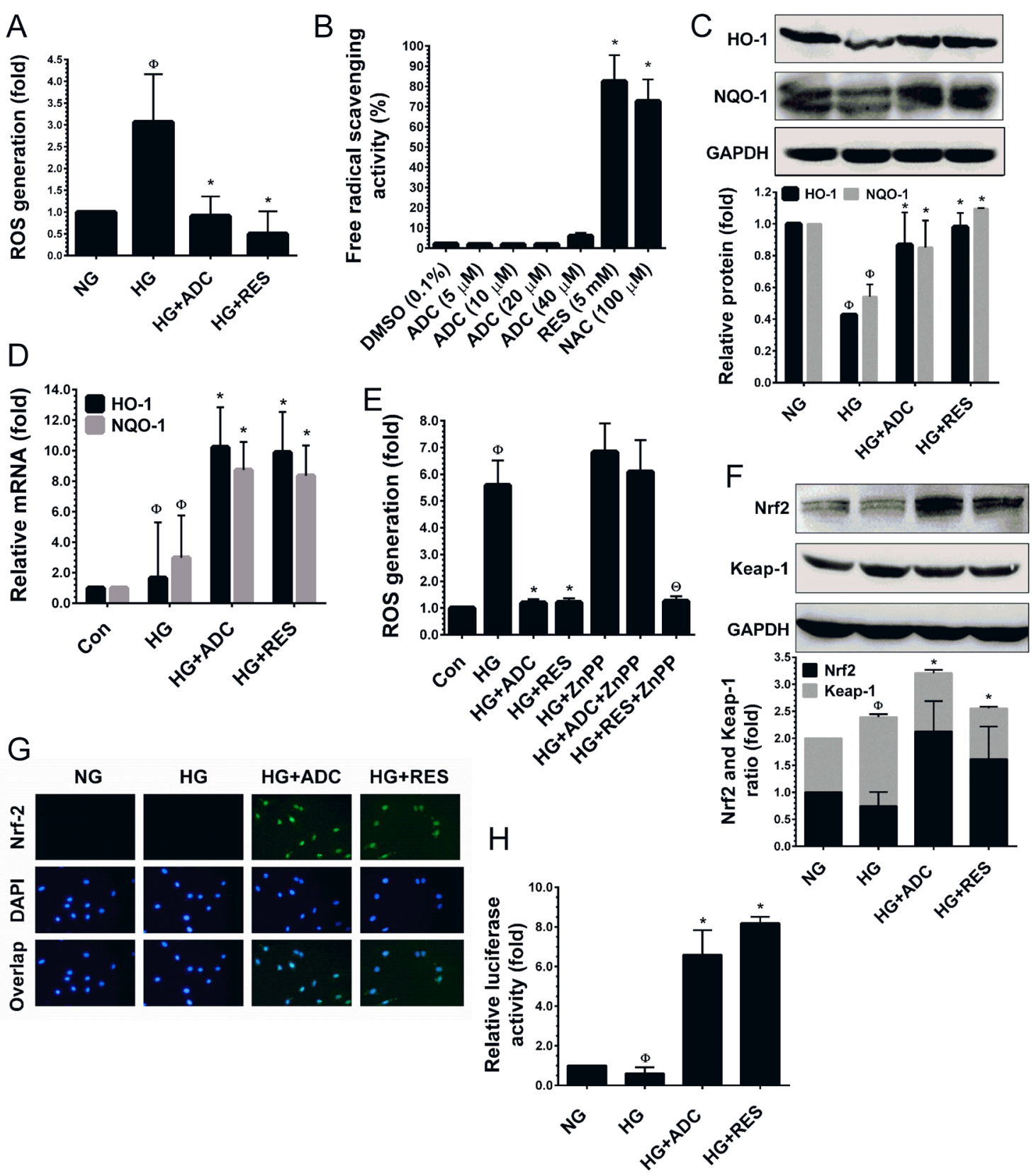

Figure 4: ADC activates Nrf2-dependent anti-oxidant defense in HUVECs. A. To determine the ROS inhibitory effect of ADC, HUVECs were incubated with HG in the presence or absence of ADC or RES for $24 \mathrm{~h}$. After incubation, intracellular ROS was measured by spectrometer using $\mathrm{DCFH}_{2}$-DA flurogenic probe. B. The free-radical scavenging activity of ADC was determined by DPPH assay. NAC and RES were used as positive controls. C.,F. Cells were treated with HG in the presence or absence of ADC or RES for 24 h. The protein levels of HO-1, NQO-1, Nrf2 and Keap-1 were determined by western blot analysis. D. To quantify the mRNA expression levels of HO-1 and NQO-1, HUVECs were incubated with HG in the presence or absence of ADC or RES for $24 \mathrm{~h}$. Total RNA was subjected to Q-PCR analysis. Relative mRNA levels were normalized with $\beta$-actin mRNA. E. HUVECs were pre-treated with $\mathrm{ZnPP}(10 \mathrm{mM}) \mathrm{for} 2 \mathrm{~h}$ and then incubated with HG in the presence or absence of ADC or RES for $24 \mathrm{~h}$. Intracellular ROS was quantified by spectrophotometer. G. The protein expression and nuclear localization of Nrf2 was determined by immunofluorescence analysis. The subcellular and nuclear localization of Nrf2 was photographed using a fluorescence microscope. DAPI was used to stain the nucleus. H. To determine the Nrf2 transcriptional activity, HUVECs were transiently transfected with ARE promoter construct using ipofectamine and incubated with HG in the presence or absence of ADC or RES for $6 \mathrm{~h}$. Cell lysates were mixed with luciferase reagents and quantified using an illuminometer. The fold change of relative ARE promoter activity was compared with untreated cells (NG). Values represent the mean $\pm \mathrm{SD}$ of three independent experiments. Statistical significance was set at ${ }^{\Phi} P<0.05$ compared to NG $v s$. HG, $* P<0.05$ compared to HG $v s$. samples and ${ }^{\Theta} P<0.05$ compared to $\mathrm{HG}$ vs. ZnPP pre-treatment group. 
of ADC on HUVEC proliferation under HG conditions were measured by trypan blue exclusion assay. In line with a previous study [30], HUVECs maintained in the NG condition exhibited significantly greater proliferation as indicated by proliferation index (PI) value of $55.62 \pm$ $0.5 \%$ (Figure $2 \mathrm{~F}$ ). However, a dramatic reduction in cell proliferation was observed in the HG condition $(37.7 \pm$ 7.7\%). The HG-mediated inhibition of cell proliferation was significantly prevented by ADC as shown by the increased PI value of $57.17 \pm 0.7 \%$ (Figure $2 \mathrm{~F}$ ). Since, reduced cell proliferation is a common hallmark of cellcycle arrest, we further clarified these results with cellcycle analysis. Cell-cycle distribution, measured by flow cytometry indicated that treatment with $\mathrm{HG}$ arrested
HUVECs at the $\mathrm{G}_{1}-\mathrm{S}$ transition phase as evidenced by an increased cell population at the $\mathrm{G}_{0} / \mathrm{G}_{1}$ phase, by $62.3 \%$ from $44.4 \%$ (NG). This effect was significantly attenuated by co-treatment with ADC which kept the percentage of cells at the $\mathrm{G}_{0} / \mathrm{G}_{1}$ phase near the control value (42.8\%) (Figure 2G). To further clarify this effect, cell-cycle regulatory proteins, such as cyclins and cyclin-dependent kinases (CDKs) were examined by immunoblotting. Our results strongly support the notion that $\mathrm{G}_{1}-\mathrm{S}$ transition phase regulatory proteins, particularly cyclin D1, CDK4, CDK6, cyclin E and CDK2 were significantly downregulated by $\mathrm{HG}$. However, co-treatment with ADC significantly blocked HG-mediated reduction in cyclin and CDK protein levels (Figure 2G). In addition, treatment
A

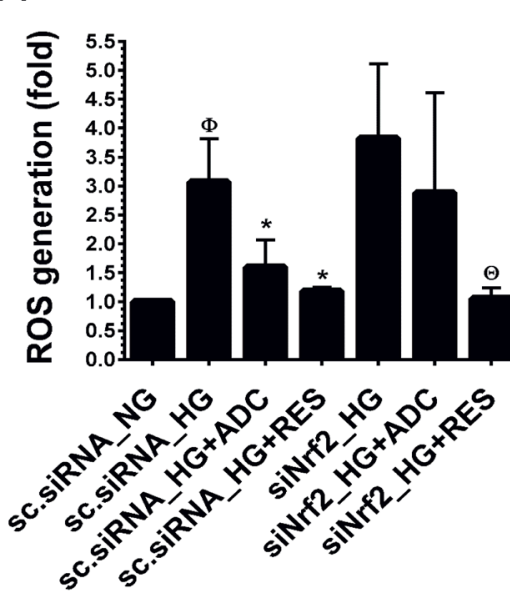

C

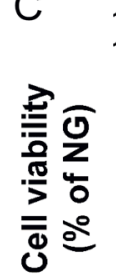

B
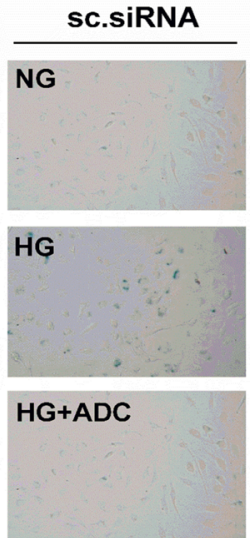

HG+RES
siNrf2

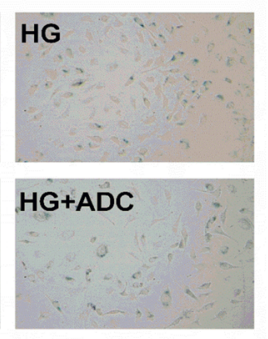

HG+RES
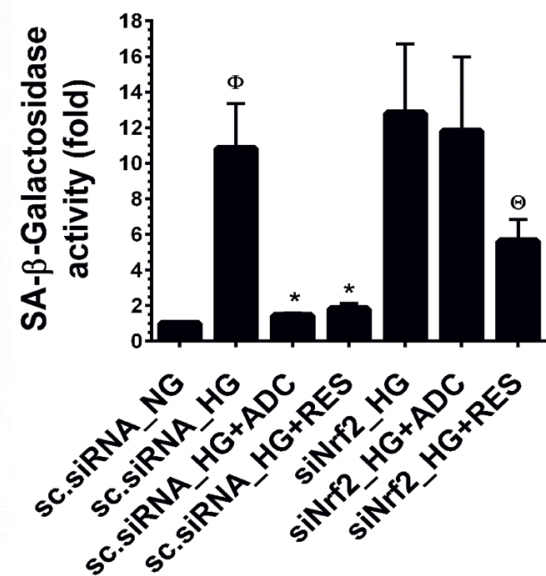

$\mathrm{D}$

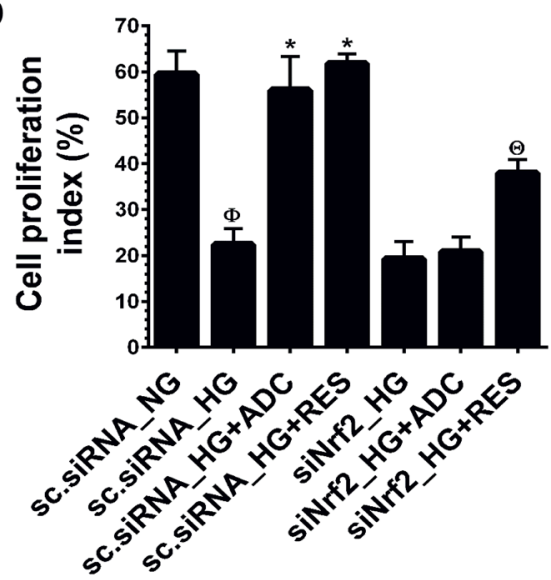

Figure 5: ADC has a protective effect in Nrf2 silenced cells. HUVECs were transfected with specific siRNA against Nrf2 or scrambled siRNA. After transfection for $24 \mathrm{~h}$, cells were incubated with HG in the presence or absence of ADC or RES for 24-72 h. A. Intracellular ROS was measured by $\mathrm{DCFH}_{2}$-DA assay using a fluorescence spectrophotometer. Total RNA was extracted and subjected to Q-PCR analysis to determine HO-1 and NQO-1 mRNA expression levels. B. SA- $\beta$-gal activity was determined by SA- $\beta$-gal assay kit after incubation for $72 \mathrm{~h}$. The left panel shows representative figures and right panel shows quantitative analysis of SA- $\beta$-gal positive cells per microscopic field. C. Cell viability was determined by MTT colorimetric assay. D. Cell proliferation index was determined by flow cytometry. Values represent the mean $\pm \mathrm{SD}$ of three independent experiments. Statistical significance was set at ${ }^{\Phi} P<0.05$ compared to NG vs. HG, $* P<0.05$ compared to $\mathrm{HG} v$ s. samples and ${ }^{\Theta} P<0.05$ compared to $\mathrm{HG}$ vs. siNrf2 transfection group. 
with HG in the presence or absence of ADC or RES did not show any alteration in protein levels of cyclin B1 and $\mathrm{cdc} 2$, which are involved in the $\mathrm{G}_{2}-\mathrm{M}$ transition phase.

\section{ADC inhibits HG-induced endothelial cell senescence}

A significant increase in SA- $\beta$-gal positive HUVECs was observed at $48 \mathrm{~h}$ and reached a maximum level at 72 $\mathrm{h}$ after treatment with HG. SA- $\beta$-gal activity in HUVECs treated with $\mathrm{HG}$ reached $6.5 \pm 2.3$-fold after $72 \mathrm{~h}$, whereas the increased SA- $\beta$-gal positive cells were significantly reduced to $0.6 \pm 0.3$-fold and $1.0 \pm 0.7$-fold by cotreatment with ADC and RES, respectively (Figure 3A). Senescence marker protein 30 (SMP30), also known as regucalcin, is a $34 \mathrm{kDa}$ cytosolic marker protein for aging. Loss of SMP30 expression was frequently observed in senescent cells [31]. Previous studies have reported that exposure of endothelial cells to $\mathrm{HG}(30 \mathrm{mM})$ rapidly decreases SMP30 expression in vitro $[13,32]$. Therefore, we examined the protein expression level of SMP30 using immunofluorescence analysis. Concomitant with previous studies [13, 32], the endogenous expression of SMP30 was significantly reduced by $\mathrm{HG}(30 \mathrm{mM})$ as observed by a reduction in fluorescence positive cells. However, treatment with ADC $(10 \mu \mathrm{M})$ or RES $(5 \mu \mathrm{M})$ significantly increased SMP30 expression as evidenced by increased fluorescence positive cells (Figure 3B). This data was further confirmed by western blot analysis. Cotreatment with ADC $(10 \mu \mathrm{M})$ or $\operatorname{RES}(5 \mu \mathrm{M})$ significantly ameliorated $\mathrm{HG}$-induced reduction in SMP30 protein levels. Interestingly, the increase in SMP30 protein level in ADC or RES treated cells under the HG condition was higher than that at the basal level (Figure 3C).

Increased levels of cyclin-dependent kinase inhibitors (CKIs), such as $\mathrm{p} 16^{\mathrm{INK} 4 \mathrm{~A}}$ and $\mathrm{p} 21^{\mathrm{CIP} 1}$ were frequently observed in senescent or aging cells [33]. Maeda et al. [34] reported a remarkable increase of $\mathrm{p} 16^{\mathrm{INK} 4 \mathrm{~A}}$ and $\mathrm{p} 21^{\mathrm{CIP} 1}$ protein levels were noted in endothelial cells exposed to intermediate high glucose (22 $\mathrm{mM}$ ) for 3 days. Therefore, we further examined whether the effect of ADC on HG-induced HUVEC senescence was associated with parallel changes in the expression of $\mathrm{p} 16^{\mathrm{INK} 4 \mathrm{~A}}$ and $\mathrm{p} 21^{\mathrm{CIP} 1}$, proteins that are involved in endothelial cell senescence. As we expected, compared with NG-treated cells, the protein expression levels of p $16^{\mathrm{INK} 4 \mathrm{~A}}$ and $\mathrm{p} 21^{\mathrm{CIP} 1}$ were significantly up-regulated by $\mathrm{HG}$ (4.02-fold and 5.2-fold, respectively). However, treatment with ADC reduced the protein levels of $\mathrm{p} 16^{\mathrm{INK} 4 \mathrm{~A}}$ and $\mathrm{p} 21^{\mathrm{CIP} 1}$ to 1.6 -fold and 2.5-fold, respectively in HUVECs under HG conditions (Figure 3D). This effect was further confirmed by immunofluorescence analysis. Increased p $21^{\mathrm{CIP} 1}$ expression levels were observed in HG-only treated cells, whereas low p $21^{\mathrm{CIP} 1}$ expression levels were noted in ADC or RES treated cells under HG conditions
(Figure 3E). During premature cellular senescence, aberrant activation of oncogenes and oxidative stress has been reported. Particularly, when cells are damaged, they withdraw from the cell-cycle and try to repair damage by activating the $\mathrm{p} 53-\mathrm{p} 21^{\mathrm{CIP} 1}$ and retinoblastoma protein $(\mathrm{Rb})-\mathrm{p} 16^{\mathrm{INK} 4 \mathrm{~A}}$ pathways [35-37]. To determine whether ADC regulates HUVE senescence via altering the p53 pathway, we examined the levels of p53 phosphorylation and acetylation under $\mathrm{HG}$ conditions. Results from immunofluorescence analysis revealed that exposure of HUVECs to HG for $72 \mathrm{~h}$ significantly increased p53 acetylation as evidenced by increases in fluorescence in HUVECs. However, reduced fluorescence intensity was observed in ADC or RES co-treatment groups, showing that ADC and RES significantly blocked HG-mediated acetylation of p53 (Figure 3F). This effect was further confirmed by immunoblotting. As shown in Figure 3G, compared with the NG treatment group, a remarkable increase in p53 acetylation (Ac-p53) was observed after treatment with $\mathrm{HG}$ for $72 \mathrm{~h}$ (2.9-fold), whereas increases in Ac-p53 levels were significantly attenuated in the presence of ADC. Indeed, positive control REStreated cells showed a complete inhibition of Ac-p53 in HUVECs under HG. In contrast to the ADC effect on p53 acetylation, ADC or RES failed to restore $\mathrm{HG}$-induced reduction in $\mathrm{p} 53$ phosphorylation (p-p53), indicating that ADC or RES prevent p53 acetylation without affecting its phosphorylation (Figure 3G). Hypo-phosphorylation (active form) of the retinoblastoma protein ( $\mathrm{Rb}$ ) is observed in most senescent cells [38]. To further examine whether ADC modulates high glucose-induced dephosphorylation of $\mathrm{Rb}$ in HUVECs, we monitored the phosphorylated form of $\mathrm{Rb}(\mathrm{p}-\mathrm{Rb})$ using western blot analysis with specific antibody. A dramatic reduction in $\mathrm{Rb}$ phosphorylation was observed after treatment with $\mathrm{HG}$ (0.4-fold), whereas co-treatment with ADC significantly prevented HG-mediated de-phosphorylation and increased it to 1.7-fold (Figure $3 \mathrm{H}$ ). However, the total form of $\mathrm{Rb}$ was unaffected by either HG or ADC.

\section{ADC modulates HG-induced overproduction of ROS in HUVECs}

It is well-known that hyperglycemia can increase ROS accumulation, which is the prevailing mechanism leading to endothelial cell dysfunction $[13,39]$. Therefore, we hypothesized that ADC could modulate HG-induced senescence in HUVECs through the inhibition of ROS generation. To determine the efficacy of ADC in reducing HG-induced ROS generation, we used a cell-permeable fluorescent dye $\mathrm{DCFH}_{2}$-DA which fluorescences upon oxidation by ROS. As shown in Figure 4A, compared with NG-treated cells, a remarkable increase of intracellular ROS (3.06-fold) was observed in HUVECs. However, co-treatment with ADC strongly inhibited this increase 
reverting ROS to basal levels (0.91-fold) under HGinduced conditions. Indeed, treatment with RES further reduced the basal level of ROS to 0.49 -fold lower than that in the $\mathrm{HG}$ condition. This data suggests that ADC
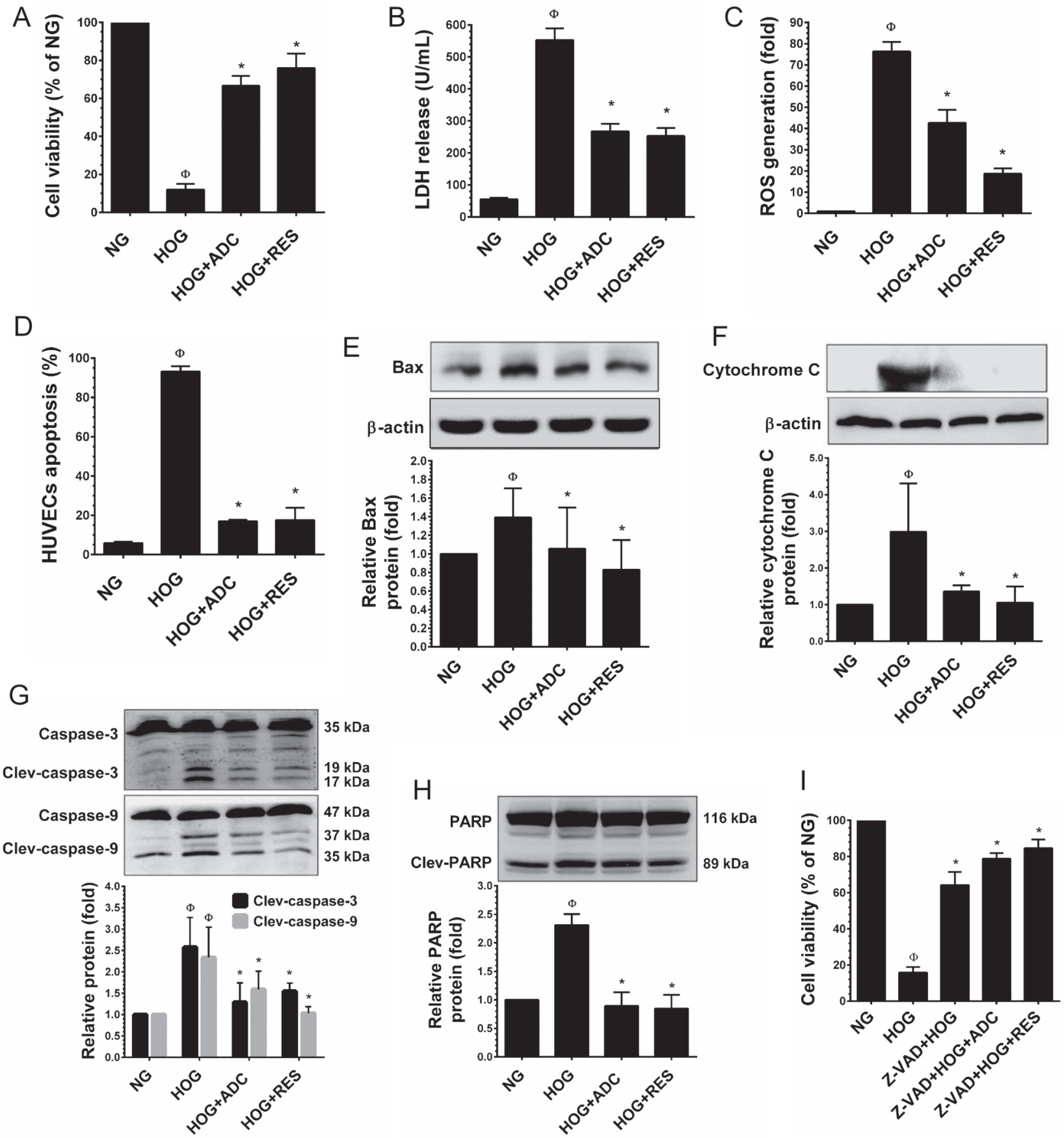

Figure 6: ADC protects HUVECs from hyperosmotic glucose (HOG)-induced cell death. HUVECs were incubated with HOG in the presence or absence of ADC or RES for $24 \mathrm{~h}$. A. Cell viability was determined by MTT colorimetric assay. B. HUVEC injury was determined by LDH release into the culture media. C. Intracellular ROS generation was quantified by DCFH - DA flurogenic assay. D. Apoptosis was determined by Annexin V/PI staining assay. E.,F. Protein levels of Bax and cytochrome C levels were measured by western blot analysis. The relative protein levels of Bax and cytochrome $\mathrm{C}$ were normalized with $\beta$-actin. G.,H. The activation (cleaved form) of caspase-9, caspase-3 and PARP were determined by western blot analysis and the protein levels were normalized with their corresponding pro-form. I. HUVECs were pre-incubated with caspase-3 inhibitor (Z-VAD-FMK, $30 \mu \mathrm{M})$ for $2 \mathrm{~h}$ and then incubated with HG in the presence or absence of ADC or RES for $24 \mathrm{~h}$. The cell viability was determined by MTT assay. Values represent the mean \pm SD of three independent experiments. Statistical significance was set at ${ }^{\Phi} P<0.05$ compared to NG $v s$. HG and $* P<0.05$ compared to HG $v s$. samples. 
may possess strong anti-oxidant properties. However, the underlying mechanism of this action was unclear. To unravel the mechanism, next we examined whether ADC possess direct free-radical scavenging ability by performing a cell-free DPPH free radical scavenging assay with various doses of ADC (1-40 $\mu \mathrm{M})$. As shown in Figure 4B, ADC up to the concentration of $20 \mu \mathrm{M}$ did not show free-radical scavenging effect in a cell-free system, whereas ADC at $40 \mu \mathrm{M}$ did show an effect (6.08\%) which was statistically not significant to the control group. The known anti-oxidants, NAC and RES exhibited potent free-radical scavenging effects of $82.5 \%$ and $64.67 \%$, respectively.

\section{ADC prevents $\mathrm{HG}$-mediated reduction in $\mathrm{HO}-1$ and NQO-1 expression in HUVECs}

Previous studies have demonstrated that $A$. cinnamomea or its components possess strong anti-oxidant effects through acting as direct free-radical scavengers or activators of cellular anti-oxidant genes [23, 25]. Bearing this in mind, we hypothesized that ADC may eliminate intracellular ROS through the induction of anti-oxidant genes. We found that exposure of HUVECs to HG for $72 \mathrm{~h}$ reduced the activity of the endogenous anti-oxidant system as evidenced by reduction in protein levels of $\mathrm{HO}-1$ and NQO-1 to 0.42-fold and 0.54-fold, respectively (Figure 4C). However, treatment with ADC significantly prevented the HG-mediated reduction in HO-1 and NQO-1 protein levels and restored them to nearly basal level, 0.86-fold and 0.85-fold, respectively (Figure 4C). This effect was further confirmed by Q-PCR analysis, which showed that treatment with ADC significantly augmented HO-1 and NQO-1 mRNA expression by 10.2-fold and 8.7-fold respectively (Figure 4D). Further, to clarify the importance of ADC-mediated induction of HO-1, ROS inhibition was determined under HO-1 inhibited conditions. HUVECs were pretreated with a pharmacological dose of $\mathrm{ZnPP}$ and treated with $\mathrm{HG}$ in the presence or absence of ADC or RES. As shown in Figure 4E, an elevated level of ROS (6.8-fold) caused by $\mathrm{HG}$ was observed in $\mathrm{ZnPP}$-treated cells. Co-treatment with ADC failed to inhibit the HGinduced ROS generation in ZnPP-treated cells (6.09-fold). This data clearly demonstrates that HO-1 plays a central role in ADC-mediated anti-oxidant effects.

\section{ADC increases Nrf2 transcriptional activity in HG-induced HUVECs}

It has been well demonstrated that HO-1 and NQO1 are activated by $\mathrm{Nrf} 2$, a major transcription factor regulating ARE-dependent anti-oxidant gene expression [22]. We, therefore, attempted to determine whether ADCmediated HO-1 and NQO-1 expression are associated with Nrf2 activity. As shown in Figure 4F, HUVECs exposed to $\mathrm{HG}$ reduced the levels of $\mathrm{Nrf} 2$ protein, whereas $\mathrm{ADC}$ or RES increased the protein level to 2.1-fold and 1.6fold above the basal level, respectively. In addition, we found that $\mathrm{HG}$ exposure significantly increased the protein level of Keap-1 (1.64-fold), an endogenous inhibitor of Nrf2. However, treatment with ADC significantly inhibited Keap-1 expression (1.07-fold), this is similar to the basal level (Figure 4F). Next, to determine the transcriptional activity of Nrf2, we monitored the nuclear translocation of $\mathrm{Nrf} 2$ by immunofluorescence analysis. Immunofluorescence staining showed that there was no detectable Nrf2 signal in HG-treated cells in either the cytoplasm or nucleus. A basal level of Nrf2 in the cytoplasm was observed in the control cells (NG). Indeed, nuclear accumulation of $\mathrm{Nrf} 2$ was significantly increased when the cells were co-treated with ADC (Figure 4G). Furthermore, to demonstrate that ADC facilitates Nrf2 transcriptional activity in HUVECs under the $\mathrm{HG}$ condition, we used the ARE-dependent luciferase reporter system. As shown in Figure $4 \mathrm{H}$, the luciferase activity in HUVECs transfected with the ARE reporter construct was significantly reduced by $\mathrm{HG}$ (0.6-fold), whereas a 6.5 -fold increase in luciferase activity was observed in the ADC co-treatment group. This data strongly supports our hypothesis that ADC eliminates HG-induced ROS generation through the activation of Nrf2-dependent antioxidant genes.

\section{ADC failed to modulate HG-mediated dysfunction in Nrf2 silenced HUVECs}

To demonstrate the involvement of Nrf2 in ADCmediated anti-oxidant effects, we developed an $\mathrm{Nrf} 2$ gene knockdown model using Nrf2 siRNA. As shown in Figure 5A, a 3-fold increase in ROS generation in response to $\mathrm{HG}$ was observed in scrambled siRNA (control siRNA) transfected cells, whereas co-treatment with ADC significantly reduced this increase to 1.5 -fold. Although, treatment with HG in the presence or absence of ADC showed a 3.8-fold increase of ROS generation in siNrf2 transfection. This increase was slightly reduced by ADC (2.8-fold) under similar conditions. Interestingly, treatment with RES significantly reduced ROS generation in both control siRNA or siNrf2-transfected cells, which may be attributed to its direct ROS scavenging ability. To further clarify this protective effect, HG-induced senescence was measured by SA- $\beta$-gal staining. In control siRNA transfected cells, a 10 -fold increase of SA- $\beta$-gal activity was observed compared with NG-treated cells, whereas co-treatment with ADC significantly blocked this effect and reduced SA- $\beta$-gal activity to 1.4 -fold (Figure $5 B)$. However, a remarkable increase in SA- $\beta$-gal activity (12.8-fold) was observed in siNrf2 knockdown cells under HG. Co-treatment with ADC failed to inhibit HGinduced SA- $\beta$-gal activity in siNrf2 knockdown cells as 


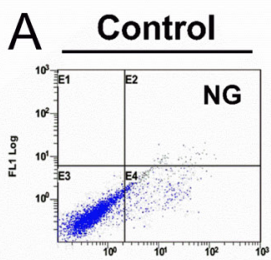

FLSLog
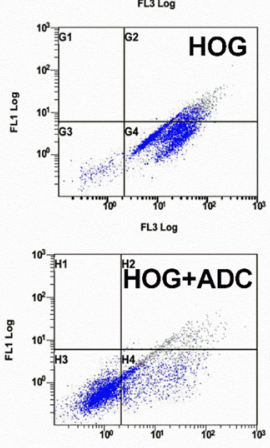

FL3Lo
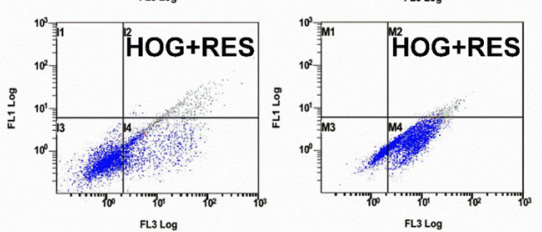

B
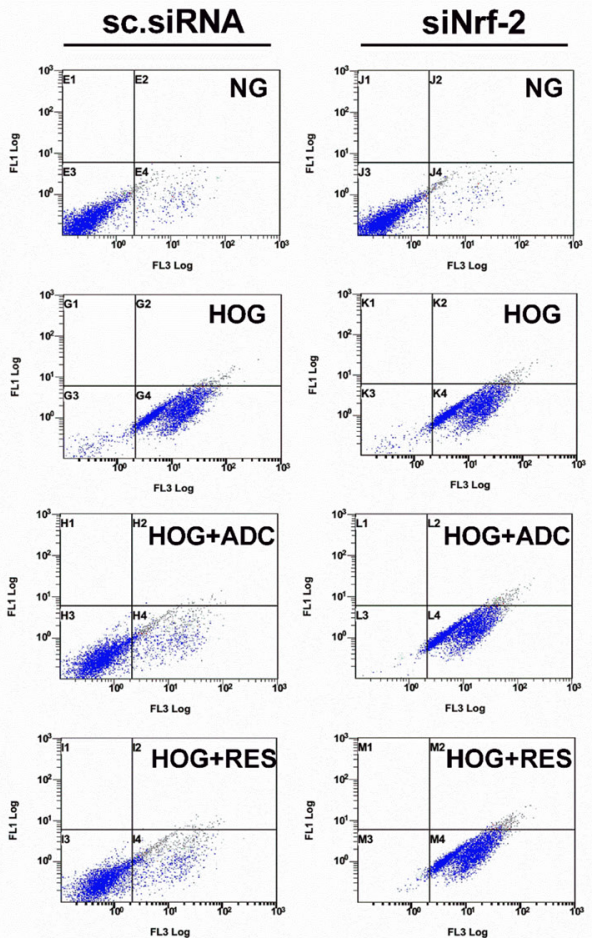
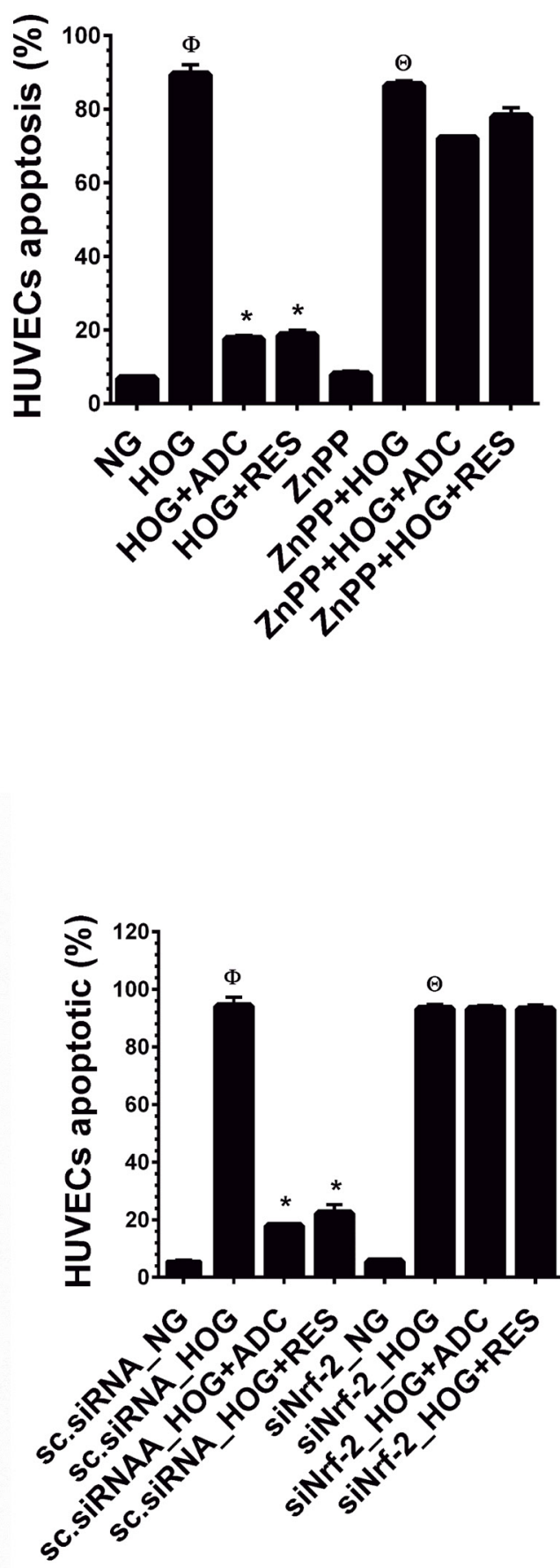

Figure 7: ADC failed to protect HOG-induced HUVEC apoptosis under Nrf2 silenced conditions. A. HUVECs were transfected with specific siRNA against Nrf2 or scrambled siRNA (control). After transfection for $24 \mathrm{~h}$, cells were incubated with HOG in the presence or absence of ADC or RES for $24 \mathrm{~h}$. HUVEC apoptosis was determined by Annexin V/PI staining using a flow cytometer. B. HUVECs were pre-treated with ZnPP for $2 \mathrm{~h}$ and then incubated with HOG in the presence or absence of ADC or RES for $24 \mathrm{~h}$. Apoptotic cell death was quantified by flow cytometry. Values represent the mean $\pm \mathrm{SD}$ of three independent experiments. Statistical significance was set at ${ }^{\oplus} P<0.05$ compared to NG vs. HG, ${ }^{*} P<0.05$ compared to HG vs. samples and ${ }^{\oplus} P<0.05$ compared to NG $v$. HOG in siNrf2 transfected cells. 
evidenced by 11.8 -fold SA- $\beta$-gal activity (Figure 5B). Next, to examine the involvement of ADC-mediated Nrf2 activation in HG-induced growth arrest, proliferation and cell-cycle analysis were performed. As shown in Figure 5C, compared to HG-treated cells (46.3\%), co-treatment with ADC significantly increased the number of viable cells to $80.6 \%$ in control siRNA transfected cells, whereas the percentage of viable cells in siNrf2 transfected cells declined to $34 \%$ by HG. ADC failed to recover the HGmediated reduction in cell number as shown by only $26.6 \%$ of siNrf2 transfected cells being viable. A similar trend was also observed in cell proliferation index: the percentage of cell proliferation in HG-treated scsiRNA and siNrf2 transfected cells declined to $22.3 \pm 3.4 \%$ and $19.2 \pm 3.8 \%$, respectively, whereas cells were transfected with scsiRNA under NG condition showed $59.5 \pm 5.0 \%$ of proliferation. ADC treatment also did not exhibit any significant increase in cell proliferation under the siNrf2 system $(20.8 \pm 3.12 \%)$ whereas a significant increase in cell proliferation was observed in ADC-treated control siRNA transfected cells $(56.03 \pm 7.2 \%$ (Figure 5D). These data strongly suggest that ADC-mediated induction of anti-oxidant genes modulates HG-induced endothelial cell dysfunction.

\section{ADC protects HUVECs from hyperosmolality- induced apoptosis}

It has been demonstrated that exposure of HUVECs to a hyperosmolar concentration of glucose (HOG, 60 $\mathrm{mM}$ ) for 24-48 h, increased rapid apoptosis and HUVEC

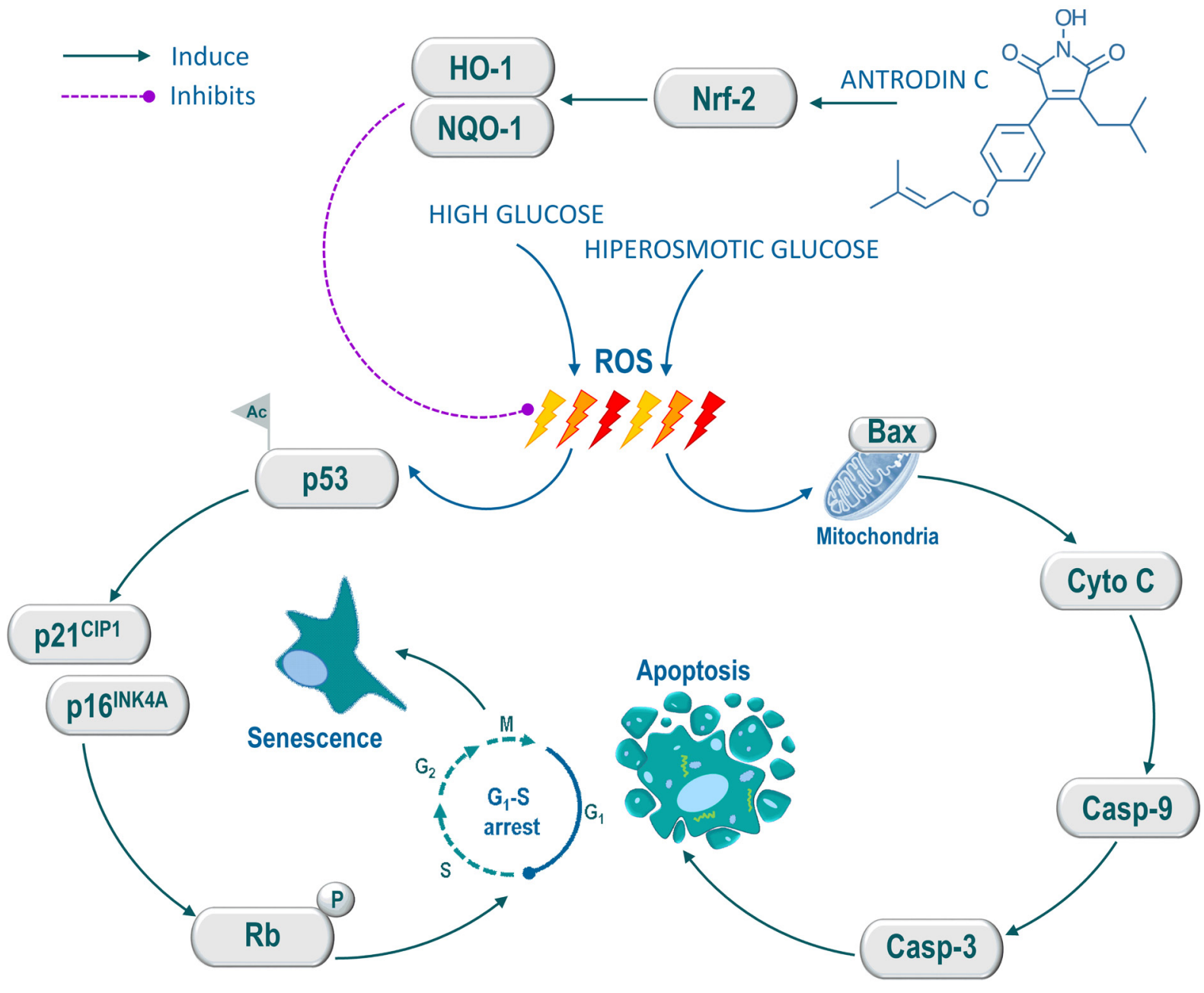

Figure 8: Schematic representation of antrodin C-mediated protection against high glucose or hyperosmotic glucoseinduced senescence and apoptosis in human endothelial cells. High glucose induces intracellular ROS, which triggers p53 acetylation. Activated $\mathrm{p} 53$ up-regulates $\mathrm{p} 16^{\mathrm{INK} 4 \mathrm{~A}}$ and $\mathrm{p} 21^{\mathrm{CIP} 1}$, which further activates $\mathrm{Rb}$, thereby the cell-cycle was arrested at $\mathrm{G}_{1}-\mathrm{S}$ transition and induced cellular senescence. Conversely, hyperosmotic glucose induce aberrant cellular ROS production, which eventually induce apoptosis in HUVECs. However, treatment with antrodin C activates Nrf2-dependent anti-oxidant genes such as HO-1 and NQO-1 followed by degradation of Keap-1, which facilitates ROS inhibition and its down-stream cascades including cell-cycle arrest, senescence and apoptosis in human endothelial cells. 
injury. Therefore, we further examined whether ADC could protect endothelial cells from hyper glucose-induced cell death. As shown in Figure 6A, exposure of HUVECs to HOG for 24 significantly reduced the cell viability to $12 \%$, which was significantly protected by ADC and the cell viability was increased to $66.6 \%$. In addition, an elevated level of LDH (552.3 units $/ \mathrm{mL})$ in culture media was observed when HUVECs were incubated with HOG for $24 \mathrm{~h}$. However, co-treatment with ADC significantly prevented HOG-induced HUVEC injury as evidenced by decreased level of LDH (267.3 units $/ \mathrm{mL}$ ) in the culture media (Figure 6B). Further analysis revealed that HOGmediated cell death was strongly associated with over production of ROS as evidenced by the 76.3-fold increase ROS generation observed. Whereas, co-treatment with ADC significantly ameliorated HOG-induced ROS generation to $42.6 \%$ (Figure $6 \mathrm{C}$ ). Next to examine the antiapoptotic effect of ADC, HUVECs were incubated with HOG in the presence or absence of ADC or RES for $24 \mathrm{~h}$, apoptotic cell death and LDH release were measured. As shown in Figure 6D, exposure of HUVECs to HOG for 24 $\mathrm{h}$ resulted in a significant increase in cell apoptosis $(74 \%)$, whereas co-treatment with ADC prevented HOG-induced HUVEC apoptosis, which was significantly reduced to $31 \%$. Since, the over production of intracellular ROS and mitochondrial damage are inevitable, we examined the activation of the intrinsic apoptosis regulatory proteins. An elevated level of Bax, a mitochondrial membraneassociated apoptotic protein was found in HOG-treated cells (2.3-fold), which was significantly inhibited by ADC. Indeed, $\mathrm{ADC}$ reduced the Bax expression to below basal levels (0.89-fold) under the HOG condition (Figure 6E). In addition, compared with control, a remarkable increase of cytochrome C (3.9-fold) was observed in HOG treated cells, however co-treatment with ADC significantly reduced to 1.47-fold (Figure 6F). We further examined the expression level of cytochrome $\mathrm{C}$ downstream effector caspases such as caspase- 9 and caspase-3. Results showed that a 2.3 -fold and 2.5-fold increase in active (cleaved) caspase- 9 and caspase- 3 , respectively, were observed in HOG-treated cells, whereas co-treatment with ADC reduced them to 1.5 -fold and 1.29-fold, respectively (Figure 6G). Moreover, following the activation of caspase-3, an increase in PARP activation (2.3-fold) was observed in HOG treated cells that was significantly attenuated by ADC (0.89-fold) (Figure $6 \mathrm{H})$. To further confirm that the HOG-induced cell death was mediated by activation of caspase signaling events, HUVECs were preincubated with Z-VAD-FMK $(30 \mu \mathrm{M})$, a pharmacological inhibitor of caspase-3 for $2 \mathrm{~h}$ and treated with HOG in the presence or absence of ADC or RES for $24 \mathrm{~h}$. As shown in Figure 6I, compared with HOG-treated cells (15.8\%), the percentage of viable cells were significantly increased to $64.2 \%$ in Z-VAD-FMK-treated cells, which showed that HOG-induced cell death was mediated by the caspase cascade. Interestingly, the percentage of viable cells was further increased to $78.8 \%$ and $84.6 \%$, when co-incubated with ADC and RES, respectively.

\section{Nrf2-mediated anti-oxidant genes required for anti-apoptotic effect of ADC}

To further explain our hypothesis that Nrf2mediated anti-oxidant genes, at least HO-1 is required for ADC-mediated anti-apoptotic effects. HUVECs were pre-treated with $\mathrm{ZnPP}$ for $2 \mathrm{~h}$ and then incubated with HOG for $24 \mathrm{~h}$ in the presence or absence of ADC or RES. The cell apoptosis was measured by flow cytometry. As shown in Figure 7A, compared to control cells (6.8\%), the percentage of apoptotic cells were markedly increased to $89.4 \%$ in HOG-treated cells and reduced to $17.5 \%$ by ADC. Whereas, ADC failed to protect HOG-induced apoptosis in ZnPP-treated cells. A similar trend was also observed in siNrf2 knockdown cells in which ADC barely prevented HOG-induced apoptosis (Figure 7B). Essentially, these results strongly suggest that ADCmediated induction of anti-oxidant genes play a central role on its protective effects.

\section{DISCUSSION}

Cardiovascular disease (CVD) is one of the leading causes of death worldwide, and diabetes mellitus has been implicated as a major risk factor in the development of CVD [40]. Given that hyperglycemia-induced endothelial cell dysfunction is a key event in the onset and progression of CVD, protection of vascular endothelial cells from such dysfunction represents an important strategy for the diagnosis of CVD. The medicinal fungus A. cinnamomea and its bioactive components exhibit a variety of bioactivities, including anti-diabetic and antihyperlipidemic properties in vivo [41]. We previously reported that Antrodin $\mathrm{C}$, a maleimide derivative isolated from the mycelia of $A$. cinnamomea inhibits TGF- $\beta$ induced breast cancer cell metastasis via inhibition of epithelial-to-mesenchymal transition in vitro [29]. Another study shows that $\mathrm{ADC}$ inhibits hepatitis $\mathrm{C}$ virus $(\mathrm{HCV})$ protease activity in vitro [42]. However, other biological effects of this potentially beneficial compound are not well elucidated. In the present study, we used an in vitro model of HUVECs to investigate the protective effects of ADC on high glucose-accelerated endothelial cell dysfunction. To our knowledge this is the first report demonstrating that ADC can inhibit hyperglycemia-induced endothelial cell dysfunction via inhibition of ROS generation, senescence, growth arrest and apoptosis in cultured HUVECs. These data indicate that ADC might be a potential candidate for the prevention of diabetic-associated vascular complications.

In line with previous studies [30, 43, 44], HUVECs exposed to HG exhibited a dose- and time-dependent 
reduction in cell viability. The anticipated HG-induced reduction in HUVEC viability was significantly restored by ADC. A similar effect was also observed with RES, the known anti-oxidant treatment group. In addition, we found that HG inhibited the proliferation of HUVECs, and this effect was significantly blocked by ADC. It has been well demonstrated that HG triggers endothelial cell apoptosis in a selective and specific manner, since endothelial cell apoptosis was barely observed in cells treated with the osmotic glucose mannitol $[13,44]$. Furthermore, previous reports indicate that $\mathrm{HG}(30 \mathrm{mM})$, which is an ambient dose for inducing endothelial cell apoptosis, failed to cause apoptosis in other standardized cells lines such as K-562 (leukemia), P815 (mast cell) YT (nature killer cell) and CCD966SK (skin fibroblast) $[45,46]$. In this study, we found that incubation of HUVECs with HG (30 $\mathrm{mM}$ ) for $72 \mathrm{~h}$ significantly increased apoptosis (17.6\%), whereas a remarkable and rapid increase of apoptosis (74\%) was observed when HUVECs were incubated with very high dose of glucose $(60 \mathrm{mM})$. This increase of apoptosis was achieved within $24 \mathrm{~h}$. Furthermore, HGmediated endothelial cell necrosis, another form of cell death was measured by LDH release assay. We found that HG $(30 \mathrm{mM})$, which induced apoptosis failed to cause necrosis of HUVECs as evidenced by unaltered levels of LDH. However, incubation of HUVECs with very high concentration of glucose $(60 \mathrm{mM})$ for $24 \mathrm{~h}$ resulted in a hyperosmolarity-associated HUVEC necrosis, indicated by elevated levels of LDH. These results were highly consistent with a previous report in which HG $(30 \mathrm{mM})$ induced apoptosis in HUVECS without causing HUVEC necrosis, whereas treatment with $\mathrm{HG}(60 \mathrm{mM})$ remarkably increased HUVEC apoptosis as well as necrosis, which was not protected by taurine, an organic compound widely found in animal tissues [44]. Interestingly, co-treatment with ADC prevents both HG $(30 \mathrm{mM})$ and $\mathrm{HG}(60 \mathrm{mM})-$ induced HUVEC apoptosis and necrosis without any compromise.

It is well-known that mitochondria play a pivotal role in cell death transduction because loss of membrane integrity $(\Delta \Psi \mathrm{m})$ causes the release of cytochrome $\mathrm{C}$ into the cytosol, which subsequently triggers caspase cascade activation [47]. Therefore, detection of the mitochondrial membrane potential provides an early detection of the initiation on apoptosis. Earlier studies revealed that exposure of endothelial cells to HG increase loss of membrane potential and eventually cause apoptosis [39]. According to the data, we found that HUVECs exposed to HG increase mitochondrial membrane permeability as evidenced by increase in cytochrome $\mathrm{C}$ and Bax protein levels in the cytosol. However, HUVECs treated with ADC significantly reduced mitochondrial membrane potential as indicated by reduction in cytochrome $\mathrm{C}$ and Bax levels. Activation of caspase-3 resulted in DNA fragmentation, a characteristic feature of cell apoptosis [47]. Ho et al. [48] reported that in HUVECs incubated with $\mathrm{HG}$, a significant increase in cleavage of initiator caspases, such as caspase-9 and effector caspases like caspase-3 were observed. In addition, Garcia Soriano et al. [49] demonstrated that endothelial cells incubated in HG exhibited an over activation of PARP, a nuclear enzyme response to DNA injury. In the present study, HG-induced increases in caspase-3, caspase-9 and PARP activation were significantly prevented by ADC. This probably explains the anti-apoptotic functionality of ADC on HUVECs induced by hyperglycemia. An earlier study demonstrated that compared with pathological concentration of high glucose $(30 \mathrm{mM})$, a hyperosmolarity concentration of glucose (HOG, $60 \mathrm{mM}$ ) rapidly induced endothelial cell injury or necrosis [44]. The most important finding in this study is that ADC significantly prevents HUVECs from HOG-induced over production of ROS and cellular injury or necrosis as evidenced by reduced levels of LDH because, other anti-oxidants such as taurine failed to rescue hyperosmolarity-induced endothelial cell injury and necrosis [44].

Senescence of vascular endothelial cells plays a critical role in the pathogenesis of cardiovascular diseases, and is mainly caused by ageing, diabetes and stress [50]. Several markers are available to identify senescent cells, of which the most widely used biomarker for senescent and aging cells is senescence-associated $\beta$-galactosidase (SA$\beta$-gal) activity, which is defined as SA- $\beta$-gal activity which is detectable at pH 6.0 in senescent cells [51]. In line with previous studies $[13,46]$, the present study also showed more SA- $\beta$-gal positive cells in the HG treatment group than in the NG treated group, which was significantly reversed by co-administration of ADC. Since, growth arrest is a common hallmark of cellular senescence, we examined cell-cycle progression using flow cytometry. In agreement with previous observations [52, 53], our study indicates that incubation of HUVECs with HG for $72 \mathrm{~h}$ determined a consistent reduction in cell proliferation by arresting cells at the $\mathrm{G}_{1}-\mathrm{S}$ transition phase, as evidenced by increasing the percentage of cells at the $\mathrm{G}_{0} / \mathrm{G}_{1}$ phase. However, at the same time, co-treatment with ADC significantly improved HUVEC proliferation and inhibited HG-mediated growth arrest. However, the underlying mechanisms by which HG-induced apoptosis and growth arrest in HUVECs need to be elucidated. Hyperglycemiainduced ROS production has been implicated as one of the mediators that triggers apoptosis and growth arrest in various cell types including endothelial cells $[39,44$, 46]. Although, impaired anti-oxidant defense increased oxidative stress and contributed to the development of diabetic CVD. Thus, scavenging of intracellular ROS by membrane permeable anti-oxidants or activating endogenous anti-oxidative defense by external stimuli could provoke HG-induced oxidative stress, thereby blocking endothelial cell dysfunction [19].

Mounting evidence indicates that natural products are the major source of anti-oxidants, such as flavonoids, 
terpenoids, quinones, caratinoids, vitamins, polyphenols and polysaccharides. These components act as free-radical scavengers and also regulate anti-oxidative pathways and gene expression patterns. In addition, recent reports also indicate that ergothionene, a type of amino acid protects endothelial cells from $\mathrm{HG}$-induced oxidative stress and cellular senescence through the direct inhibition of intracellular $\operatorname{ROS}[54,55]$. Therefore, we further investigated whether ADC acts as a direct antioxidant that scavenges or quenches free radicals or eliminates intracellular ROS by activation of the endogenous antioxidative defense system. Because, several lines of evidence indicated that components of $A$. cinnamomea exhibited potent anti-oxidative effects by direct freeradical scavenging or induction of anti-oxidant genes [23-25, 46, 56], initially, a cell-free DPPH assay was performed to examine direct free-radical scavenging activity of ADC. The results of DPPH assay showed that ADC does not scavenge free-radicals up to a dose of 20 $\mu \mathrm{M}$, a statistically not significant increase of free-radical scavenging activity was observed at $40 \mu \mathrm{M}$, which is correlated with our previous work in which we reported that antcin $\mathrm{M}$, a steroid like compound isolated from $A$. cinnamomea failed to scavenge free-radicals in a cellfree system, whereas inhibits ROS generation through the activation of Nrf2-dependent antioxidant genes [46]. RES and NAC are known anti-oxidants that exhibit significant free-radical scavenging activity in cell-free systems [57, 58]. These results prompted us to further examine the effects of ADC on the endogenous anti-oxidative defense mechanism, particularly, HO-1, a microsomal enzyme that catalyzes oxidation of heme into anti-oxidant molecules, biliverdin and carbon monoxide. In other hand, NQO-1, a detoxification agent remove quinonoid-medicated ROS generation in the biological systems [22]. Thus, HO-1 and NQO-1 has been recognized as an important therapeutic target of oxidative stress diseases. Growing evidence indicates that acute increase in glucose is accompanied by reduction in endogenous anti-oxidant genes that may result in endothelial cell dysfunction [59]. Our results also show a dramatic reduction in HO-1, NQO-1 and Nrf2 levels upon $\mathrm{HG}$ treatment. However, as we expected, ADC up-regulated HO-1 and NQO-1 expression in HGtreated HUVECs, thus decreasing ROS generation. Nrf2, a b-ZIP transcription factor regulates the expression of anti-oxidant genes, including HO-1 and NQO-1 [22]. We found a reduction in $\mathrm{Nrf} 2$ expression under $\mathrm{HG}$ conditions, whereas ADC up-regulated Nrf2 expression and promoted its nuclear translocation and transcriptional activity. In addition, ADC-mediated HO-1 and NQO-1 expression were significantly blocked by siNrf2, indicating that ADC prevented $\mathrm{HG}$-induced endothelial cell dysfunction through the Nrf2-mediated endogenous anti-oxidant system. However, this observation contradicted a previous report that increases of HO-1, NQO-1 and Nrf2 expression levels were observed in mouse mesangial cells which were exposed to HG for $48 \mathrm{~h}$ [60]. These findings suggest that Nrf2-mediated anti-oxidant gene expression in the $\mathrm{HG}$ condition varies according to cell type as well as treatment condition.

In conclusion, the present study provides experimental evidence that ADC prevents pathologically high glucose-induced endothelial cell dysfunction via blocking intracellular ROS generation, senescence, growth arrest and apoptosis. Our mechanistic evidence suggest that the prevention of endothelial cells likely to result from up-regulation of Nrf2-dependent anti-oxidant genes, particularly HO-1 and NQO-1, which eventually eliminates high glucose-induced oxidative stress and apoptosis of endothelial cells (Figure 8). Our study suggests that $\mathrm{Nrf} 2$ activation by ADC may represent a promising intervention in pathologically high glucoseaccelerated endothelial dysfunction as well as vascular complications.

\section{MATERIALS AND METHODS}

\section{Chemicals and reagents}

Antrodin $\mathrm{C}$ was isolated from the mycelia of $A$. cinnamomea as described previously [26]. The purity of ADC was above 99\% according to HPLC and ${ }^{1} \mathrm{H}-\mathrm{NMR}$ analyses. M199 medium, fetal bovine serum (FBS), sodium pyruvate, penicillin and streptomycin were obtained from Invitrogen (Carlsbad, CA). Endothelial cell growth supplement (ECGS), heparin sodium salt, d-Glucose, 2', 7'-dichlorofluorescein diacetate $\left(\mathrm{DCFH}_{2}-\right.$ DA), 3-(4,5-dimethyl-thiazol-2-yl)-2,5-diphenyl tetrazolium bromide (MTT), zinc protoporphyrin (ZnPP) and resveratrol (RES) were purchased from SigmaAldrich (St. Louis, CA). Antibodies against phos-Rb, cyclin D1, cyclin E, CDK2, CDK4, CDK6, Acetyl-p53, p16 ${ }^{\mathrm{INK} 4 \mathrm{~A}}, \mathrm{p} 21^{\mathrm{CIP} 1}$, phos-p53, Keap-1, Pro-caspase-3, Clevcaspase-3, Pro-caspase-9, Clev-caspase-9, Pro-PARP, Clev-PARP, Cytochrome $\mathrm{C}$ and Bax were obtained from Cell Signaling Technology, Danvers, MA. Antibodies against HO-1, NQO-1 and Nrf2 were purchased from Abcam, Cambridge, UK. Antibodies against SMP30, p53 and $\beta$-actin were obtained from Santa-Cruz Biotechnology, Dallas, TX. All other chemicals were reagent grade or HPLC grade and supplied by either Merck (Darmstadt, Germany) or Sigma-Aldrich.

\section{Cell culture and sample treatment}

Human umbilical vein endothelial cells (HUVECs) were obtained from the Bioresource Collection and Research Center (BCRC), Hsinchu, Taiwan. HUVECs were grown in M199 medium supplemented with 10\% FBS, $30 \mu \mathrm{g} / \mathrm{mL}$ ECGS, $25 \mathrm{U} / \mathrm{mL}$ heparin, $2 \mathrm{mM}$ 
L-glutamine, $1.5 \mathrm{~g} / \mathrm{L}$ sodium bicarbonate and $100 \mathrm{U} / \mathrm{L}$ penicillin and streptomycin at $37^{\circ} \mathrm{C}$ in a humidified atmosphere of $5 \% \mathrm{CO}_{2}$. Hyperglycemia treatment was induced by treating HUVECs with 15,30 and $60 \mathrm{mM}$ of d-glucose for 24-72 h. HUVEs were also incubated with $\mathrm{HG}$ in the presence or absence of ADC $(10 \mu \mathrm{M})$ or resveratrol $(5 \mu \mathrm{M})$. Controls were performed in the presence of media with normal glucose (NG, $5.5 \mathrm{mM}$ ).

\section{Cell viability assay}

HUVECs $\left(5 \times 10^{4}\right.$ cells/well $)$ were seeded in a 24 well culture plate and incubated with $\mathrm{NG}(5.5 \mathrm{mM})$ or $\mathrm{HG}(15,30$ and $60 \mathrm{mM})$ for $24-72 \mathrm{~h}$ in the presence or absence of ADC $(1-20 \mu \mathrm{M})$ or RES $(5 \mu \mathrm{M})$. Cell viability was measured by MTT colorimetric assay. Briefly, after treatment, the culture media was withdrawn and cells were incubated with MTT $(1 \mathrm{mg} / \mathrm{mL})$ in fresh medium for 2 $\mathrm{h}$ at $37^{\circ} \mathrm{C}$. The MTT formazan crystals were dissolved in $400 \mu \mathrm{L}$ of dimethyl sulfoxide (DMSO) for each well. The optical density (OD) value was measured at an absorption wavelength of $570 \mathrm{~nm}\left(\mathrm{~A}_{570}\right)$ using an ELISA microplate reader (Bio-Tek Instruments, Winooski, VT). The percentage of cell viability $(\%)$ was calculated as $\left(\mathrm{A}_{570}\right.$ of treated cells $/ \mathrm{A}_{570}$ of untreated cells $) \times 100$. Independent experiments were repeated three times and the cell viability was normalized to the NG control.

\section{Quantification of apoptosis}

Apoptotic cell death was measured according to the percentage of cells with hypodiploid DNA by using Annexin V and PI binding staining with an Annexin V/ PI Apoptosis Detection Kit (BD Bioscences, San Jose, CA). HUVECs $\left(5 \times 10^{5}\right.$ cells/dish $)$ were seeded in a 10 $\mathrm{cm}$ culture dish and treated with $\mathrm{HG}(30$ or $60 \mathrm{mM})$ in the presence or absence of ADC $(10 \mu \mathrm{M})$ or RES $(5 \mu \mathrm{M})$ for $72 \mathrm{~h}$. The control group received NG $(5.5 \mathrm{mM})$ alone over the same time course. After treatment, cells were washed twice with PBS and collected using $0.25 \%$ trypsin without EDTA, cells were pooled by centrifuging at $1500 \times g$ for $5 \mathrm{~min}$. Cells were then re-suspended in $500 \mu \mathrm{L}$ of binding buffer which contained $1 \mu \mathrm{L}$ Annexin V-FITC and $5 \mu \mathrm{L}$ PI and incubated for $5 \mathrm{~min}$ in the dark. The stained cells were analyzed directly using a flow cytometer (Beckman Coulter, Brea, CA). Data were acquired and analyzed using CXP software (Beckman Coulter). The percentage of apoptotic cells were calculated based on the percentage of Annexin V and PI staining cells in HG or sampletreated groups versus the NG-treated group.

\section{Lactate dehydrogenase (LDH) release assay}

HUVECs were seeded at a density of $5 \times 10^{4}$ cells/well in 24-well plate and incubated with various concentrations of glucose $(5.5,15,30$ and $60 \mathrm{mM})$ in the presence or absence of ADC or RES for 24-72 h. After treatment, the amount of LDH in the HUVEC culture media was determined according to the manufacturer's instruction. The LDH activity was measured at $440 \mathrm{~nm}$ using an ELISA microplate reader (Bio-Tek Instruments).

\section{Cell-cycle analyses}

To determine the effect of ADC on the cell-cycle in HG-induced HUVECs, cells were grown in 6-well plates at a density of $1 \times 10^{5}$ cells/well and treated with HG (30 $\mathrm{mM})$ in the presence or absence of ADC $(10 \mu \mathrm{M})$ or RES $(5 \mu \mathrm{M})$ for $72 \mathrm{~h}$. After treatment, cells were collected and then centrifuged for $3 \mathrm{~min}$ at $1500 \times \mathrm{g}$. Cells were fixed with $95 \%$ cold ethanol and kept at $-20^{\circ} \mathrm{C}$ overnight. The cell pellet was washed again with PBS and centrifuged at $1500 \times g$ for $3 \mathrm{~min}$, permeabilized with $1 \mathrm{~mL} \mathrm{PI/Triton}$ X-100 $(20 \mu \mathrm{g} / \mathrm{mL}$ PI, $0.1 \%$ Triton X-100 and $2.5 \mu \mathrm{g} /$ $\mathrm{mL}$ RNAse) and incubated on ice for $30 \mathrm{~min}$. The total cellular DNA content was analyzed with a flow cytometer (Beckman Coulter FC500) by acquiring at least 10,000 events. The analysis of the cell-cycle was performed by using CXP software (Beckman Coulter). The proliferation index (PI) of cells were calculated by the following formula as described previously [61]:

$$
P I(\%)=\frac{S+G_{2} / M}{G_{0} / G_{1}+S+G_{2} / M} \times 100
$$

\section{SA- $\beta$-galactosidase activity assay}

Senescence-associated $\beta$-galactosidase (SA- $\beta$-gal) activity was determined by using senescence associated $\beta$-galactosidase assay kit following the manufacturer's procedure (Cell Signaling Technology, Danvers, CA). Briefly, HUVECs were grown in 6-well plates at a density of $5 \times 10^{4}$ cells/well, and incubated with HG $(30 \mathrm{mM})$ in the presence or absence or ADC $(10 \mu \mathrm{M})$ or RES (5 $\mu \mathrm{M})$ for $72 \mathrm{~h}$. After incubation, cells were washed and fixed with $4 \%$ paraformaldehyde for $15 \mathrm{~min}$, and stained with SA- $\beta$-gal staining solution at $\mathrm{pH} 6.0$ overnight. The blue stained cells were observed and photographed under a bright-field microscope (Motic Electric Group, Xiamen, P.R. China). Number of SA- $\beta$-gal stained cells were counted/field and compared with NG. Results were expressed as the fold increase of SA- $\beta$-gal positive cells. 


\section{Determination of intracellular ROS accumulation}

Intracellular ROS accumulation in HUVECS was determined using fluorescent marker $\mathrm{DCFH}_{2}$-DA following a procedure described earlier with minor modifications [54]. Briefly, HUVECs $\left(1 \times 10^{5}\right.$ cells/ well) were seeded in 6-well plates and treated with HG $(30 \mathrm{mM})$ in the presence or absence of ADC $(10 \mu \mathrm{M})$ or RES $(5 \mu \mathrm{M})$ for 1 hour. At the end of the incubation, the culture supernatant was removed and cells were washed twice with PBS. DCFH - DA $(10 \mu \mathrm{M})$ was mixed with 500 $\mu \mathrm{L}$ M199 medium and added to the culture plate. After incubation for 30 minutes, relative fluorescence intensity was measured using a fluorescence spectrophotometer (Hidex Oy) at $485 / 535 \mathrm{~nm}\left(\mathrm{~A}_{485 / 535}\right)$. The percentage of ROS generation (\%) was calculated as $\left(\mathrm{A}_{485 / 535}\right.$ of treated cells $/ \mathrm{A}_{485 / 535}$ of NG control cells) $\times 100$.

\section{Immunofluorescence}

Immunofluorescence analysis was performed as described previously [46]. Briefly, HUVECs at a density of $1 \times 10^{4}$ cells/well were cultured in an eightwell glass Nunc Lab-Tek chamber (ThermoFisher Scientific, Waltham, MA), and treated with $\mathrm{HG}(30 \mathrm{mM})$ in the presence or absence of ADC $(10 \mu \mathrm{M})$ or RES (5 $\mu \mathrm{M})$ for 1 or $72 \mathrm{~h}$. After treatment, culture medium was removed and cells were fixed in $4 \%$ paraformaldehyde for $15 \mathrm{~min}$, permeabilized with $0.1 \%$ Triton X-100 for 10 min, washed and blocked with 10\% FBS in PBS, and then incubated overnight with the corresponding primary antibodies $(1: 200)$ in $1.5 \%$ FBS. The cells were then incubated with the fluorescein isothiocyanate (FITC)conjugated secondary antibody $(1: 1000)$ (Alexa fluor 488 , ThermoFisher Scientific) for another $1 \mathrm{~h}$ in $6 \%$ bovine serum albumin (BSA). Then, the cells were stained with $1 \mu \mathrm{g} / \mathrm{mL}$ 4',6-diamidino-2-phenylindole (DAPI, Cell Signaling Technology) for $5 \mathrm{~min}$, washed with PBS, and visualized using a fluorescence microscope (Motic Electric Group) at $40 \times$ magnification.

\section{Protein extraction and western blot analysis}

Control and treated cells were lysed in either RIPA lysis buffer or nuclear and cytoplasmic extraction reagents (Thermo Fisher Scientific) following the manufacturer's protocol. Protein content was determined by Bio-Rad protein assay reagent (Bio-Rad Laboratories, Hercules, CA). Extracted protein samples were denatured with $5 \%$ sample buffer by heating at $94^{\circ} \mathrm{C}$ for $5 \mathrm{~min}$. Equal amounts of denatured protein samples $(60 \mu \mathrm{g})$ were separated by $7-12 \%$ sodium dodecyl sulfate-poly acrylamide gel electrophoresis (SDS-PAGE) and the separated proteins were transferred onto polyvinylidene fluoride (PVDF) membrane overnight. The transferred protein membranes were incubated with $5 \%$ non-fat milk in Tris-buffered saline with Tween 20 (TBST) for $30 \mathrm{~min}$ at room temperature, followed by incubation with specific primary antibodies $(1: 1000)$ overnight, and inoculated with either horseradish peroxidase-conjugated goat antirabbit or anti-mouse antibodies (1:5000) for $2 \mathrm{~h}$. The blots were developed with enhanced chemiluminescence (ECL) western blotting reagent (Millipore, Billerica, MA) and the luminescence signals were detected by using VL ChemiSmart 3000 (Viogene Biotek, Sunnyvale, CA).

\section{RNA extraction and qPCR analysis}

Total RNA was extracted from HUVECs using Trizol Reagent (Thermo Fisher Scientific) according to the manufacturer's instructions. RNA concentration was quantified with a NanoVue Plus spectrophotometer (GE Health Care Life Sciences, Chicago, IL). An equal amount of total RNA ( $5 \mu \mathrm{g})$ was reverse-transcribed by using SuperScript III reverse transcriptase kit (Invitrogen). Quantification of mRNA expression for genes of interest was performed by qPCR using Applied Biosystems detection instruments and software (Applied Biosystems, Foster City, CA). qPCR reactions were performed with equal volume of cDNA, forward and reverse primers $(10 \mu \mathrm{M})$, power SYBR Green master mix (Applied Biosystems) under the following conditions: $96^{\circ} \mathrm{C}$ for 3 minutes followed by 40 cycles at $96^{\circ} \mathrm{C}$ for 1 minute, $50^{\circ} \mathrm{C}$ for 30 seconds and $72^{\circ} \mathrm{C}$ for 90 seconds. GAPDH was used as an internal standard to control for variability in amplification because of differences in starting mRNA concentrations. The copy number of each transcript was calculated as the relative copy number normalized by GAPDH copy number. The primer sequences of each gene for qPCR were as follows. HO-1: forward primer (F), 5'-TCAACGGCACAGTCAAGG-3'; reverse primer (R), 5'-ACTCCACGACATACTCAGC-3" NQO-1: forward primer (F), 5'-TGCGGTGCAGCTCTTCTG-3'; reverse primer (R), 5'-GCAACCCGACAGCATGC-3'; GAPDH: forward primer (F), 5'-GATCATCAGCAATGCCTCCT-3'; reverse (R), 5'-TTCCTCTTGTGCTCTTGCTG-3'.

\section{Luciferase reporter assay}

To determine the transcriptional activity of Nrf2, the antioxidant responsible element (ARE) promoter activity was determined by dual-luciferase reporter assay system (Promega, Madison, WI). Briefly, HUVECs $\left(1 \times 10^{5}\right.$ cells/ well) were seeded in 6-well plates, after achieving $~ 80 \%$ confluence, cells were incubated in Opti-MEM for $5 \mathrm{~h}$ that did not contain antibiotics. Then, cells were transfected with ARE plasmid (Qiagen, Hilden, Germany) using Lipofectamine 2000 (Invitrogen) and further incubated for $36 \mathrm{~h}$ at $37^{\circ} \mathrm{C}$. After plasmid transfection, cells were 
treated HG $(30 \mathrm{mM})$ in the presence or absence of $(10$ $\mu \mathrm{M})$ or RES $(5 \mu \mathrm{M})$ for $6 \mathrm{~h}$. Following incubation, the cells were lysed, incubated with luciferase agents and the relative luminescence intensity was quantified using a spectrophotometer (Hidex Oy, Turku, Finland).

\section{Gene silencing by siRNA}

HUVECs $\left(2.5 \times 10^{5}\right.$ cells/dish $)$ were cultured in $6 \mathrm{~cm}$ dishes, after $60 \%$ confluence at the time of transfection, culture media was replaced with $2 \mathrm{~mL}$ of Opti-MEM (Invitrogen) and cells were transfected using Lipofectamine RNAiMax (Invitrogen) transfection reagent. For each transfection, $5 \mu \mathrm{L}$ of RNAiMAX was mixed with $500 \mu \mathrm{L}$ of Opti-MEM and incubated for 5 min at room temperature. In a separate tube, siRNA (100 $\mathrm{pM}$ for a final concentration of $100 \mathrm{nM}$ in $1 \mathrm{~mL}$ OptiMEM) was added to $500 \mu \mathrm{L}$ of Opti-MEM and the siRNA solution was added to the diluted RNAiMAX reagent. The resulting siRNA/RNAiMAX mixture $(1 \mathrm{~mL})$ was incubated for an additional $25 \mathrm{~min}$ at room temperature to allow complex formation. Subsequently, the solution was added to the cells in the 6-well plates, giving a final transfection volume of $2 \mathrm{~mL}$. After incubation for $6 \mathrm{~h}$, the transfection medium was replaced with $3 \mathrm{~mL}$ of complete M199 medium and the cells were cultured at $37^{\circ} \mathrm{C}$. After transfection for $24 \mathrm{~h}$, cells were treated with HG (30 $\mathrm{mM})$ in the presence or absence of ADC $(10 \mu \mathrm{M})$ or RES $(5 \mu \mathrm{M})$ or $\mathrm{ZnPP}(10 \mu \mathrm{M})$ and subjected to subsequent experiments.

\section{Statistical data analysis}

Data are expressed as mean \pm SD. All data were analyzed using the statistical software Graphpad Prism version 6.0 for Windows (GraphPad Software, La Jolla, CA). Statistical analysis was performed using one-way ANOVA followed by Dunnett's multiple comparisons test with a $P$ value of less than 0.05 indicating statistical significance.

\section{ACKNOWLEDGMENTS}

This study was supported by the Ministry of Science and Technology, Taiwan, Republic of China (MOST-1042911- I-005-301, NSC-103-2911-I-005-301) and the Ministry of Education, Taiwan under the ATU plan.

\section{CONFLICTS OF INTEREST}

The authors have declared that no competing interests exist.

\section{Highlights}

(1)Antrodin C prevents high glucose-induced oxidative stress and endothelial cell senescence.

(2)Antrodin C blocks high glucose-induced growth arrest and apoptosis in endothelial cells.

(3)Antrodin C inhibits hyperosmotic glucoseinduced oxidative stress and HUVEC injury.

(4)HO-1 and NQO-1 anti-oxidant genes were upregulated by antrodin $\mathrm{C}$ in HUVECs.

(5)Activation of Nrf2-mediated HO-1 by antrodin C attenuated endothelial cell dysfunction.

\section{REFERENCES}

1. $\mathrm{Xu}$ J, Zou MH. Molecular insights and therapeutic targets for diabetic endothelial dysfunction. Circulation. 2009; 120:1266-1286.

2. Hossain P, Kawar B, El Nahas M. Obesity and diabetes in the developing world--a growing challenge. N Engl J Med. 2007; 356:213-215.

3. Sniderman AD, Furberg CD. Age as a modifiable risk factor for cardiovascular disease. Lancet. 2008; 371:1547-1549.

4. Favero G, Paganelli C, Buffoli B, Rodella LF, Rezzani R. Endothelium and its alterations in cardiovascular diseases: life style intervention. BioMed Res Int. 2014; 2014:801896.

5. Popov D. Endothelial cell dysfunction in hyperglycemia: Phenotypic change, intracellular signaling modification, ultrastructural alteration, and potential clinical outcomes. Int J Diebets Mellit. 2010; 2:189-195.

6. Bachschmid MM, Schildknecht S, Matsui R, Zee R, Haeussler D, Cohen RA, Pimental D, van der Loo B. Vascular aging: Chronic oxidative stress and impairment of redox signaling - consequences for vascular homeostasis and disease. Ann Med. 2013; 45:17-36.

7. Minamino T, Miyauchi H, Yoshida T, Ishida Y, Yoshida H, Komuro I. Endothelial Cell Senescence in Human Atherosclerosis. Role of Telomere in Endothelial Dysfunction. Circulation. 2002; 105:1541-1544.

8. Wang Y, Boerma M, Zhou D. Ionizing Radiation-Induced Endothelial Cell Senescence and Cardiovascular Diseases. Rad Res. 2016; 186:153-161.

9. Liu R, Liu H, Ha Y, Tilton RG, Zhang W. Oxidative Stress Induces Endothelial Cell Senescence via Downregulation of Sirt6. BioMed Res Int. 2014; 2014:13.

10. Khan SY, Awad EM, Oszwald A, Mayr M, Yin X, Waltenberger B, Stuppner H, Lipovac M, Uhrin P, Breuss JM. Premature senescence of endothelial cells upon chronic exposure to TNF $\alpha$ can be prevented by $\mathrm{N}$-acetyl cysteine and plumericin. Sci Rep. 2017; 7:39501.

11. Matsui-Hirai H, Hayashi T, Yamamoto S, Ina K, Maeda M, Kotani H, Iguchi A, Ignarro LJ, Hattori Y. DoseDependent Modulatory Effects of Insulin on GlucoseInduced Endothelial Senescence In Vitro and In Vivo: 
A Relationship between Telomeres and Nitric Oxide. J Pharmacol Exp Ther. 2011; 337:591-599.

12. Ota H, Eto M, Ako J, Ogawa S, Iijima K, Akishita M, Ouchi Y. Sirolimus and Everolimus Induce Endothelial Cellular Senescence Via Sirtuin 1 Down-Regulation. Therapeutic Implication of Cilostazol After Drug-Eluting Stent Implantation. J Am Coll Cordiol. 2009; 53:2298-2305.

13. Arunachalam G, Samuel SM, Marei I, Ding H, Triggle CR. Metformin modulates hyperglycaemia-induced endothelial senescence and apoptosis through SIRT1. Br J Pharmacol. 2014; 171:523-535.

14. Rogers SC, Zhang X, Azhar G, Luo S, Wei JY. Exposure to high or low glucose levels accelerates the appearance of markers of endothelial cell senescence and induces dysregulation of nitric oxide synthase. J Gerantol A Biol Sci Med Sci. 2013; 68:1469-1481.

15. Chen J, Goligorsky MS. Premature senescence of endothelial cells: Methusaleh's dilemma. Am J Physiol Heart Circ Physiol. 2006; 290:H1729-H1739.

16. Chen J, Huang X, Halicka D, Brodsky S, Avram A, Eskander J, Bloomgarden NA, Darzynkiewicz Z, Goligorsky MS. Contribution of p16INK4a and p21CIP1 pathways to induction of premature senescence of human endothelial cells: permissive role of p53. Am J Physiol Heart Circ Physiol. 2006; 290:H1575-H1586.

17. Ido Y, Carling D, Ruderman N. Hyperglycemia-Induced Apoptosis in Human Umbilical Vein Endothelial Cells. Inhibition by the AMP-Activated Protein Kinase Activation. Diabetes. 2002; 51:159-167.

18. Gong L, Liu FQ, Wang J, Wang XP, Hou XG, Sun Y, Qin WD, Wei SJ, Zhang Y, Chen L, Zhang MX. Hyperglycemia induces apoptosis of pancreatic islet endothelial cells via reactive nitrogen species-mediated Jun N-terminal kinase activation. Biochim Biophys Acta Mol Cell Res. 2011; 1813:1211-1219.

19. Poljsak B, Suput D, Milisav I. Achieving the balance between ROS and antioxidants: When to use the synthetic antioxidants. Oxid Med Cell Longiv. 2013; 2013:11.

20. Surh YJ. Cancer chemoprevention with dietary phytochemicals. Nat Rev Cancer. 2003; 3:768-780.

21. Senthil Kumar KJ, Wang SY. (2016) Pharmacological Applications of Lucidone: A Naturally Occurring Cyclopentenedione. In: Tsay HS, Shyur LF, Agrawal D, Wu YC, Wang SY (eds) Medicinal Plants - Recent Advances in Research and Development. Springer, Singapore. https:// doi.org/10.1007/978-981-10-1085-9_11.

22. Surh YJ, Kundu JK, Na HK. Nrf2 as a master redox switch in turning on the cellular signaling involved in the induction of cytoprotective genes by some chemopreventive phytochemicals. Planta Med. 2008; 74:1526-1539.

23. Geethangili M, Tzeng YM. Review of pharmacological effects of Antrodia camphorata and its bioactive compounds. Evid Based Complement Alternat Med. 2011;
2011:17.

24. Ao ZH, Xu ZH, Lu ZM, Xu HY, Zhang XM, Dou WF. Niuchangchih (Antrodia camphorata) and its potential in treating liver diseases. J Ethnopharmacol. 2009; 121:194212.

25. Lu MC, El-Shazly M, Wu TY, Du YC, Chang TT, Chen CF, Hsu YM, Lai KH, Chiu CP, Chang FR, Wu YC. Recent research and development of Antrodia camphorata. Pharmacol Ther. 2013; 139:124-156.

26. Nakamura N, Hirakawa A, Gao JJ, Kakuda H, Shiro M, Komatsu Y, Sheu CC, Hattori M. Five new maleic and succinic acid derivatives from the mycelium of Antrodia camphorata and their cytotoxic effects on LLC tumor cell line. J Nat Prod. 2004; 67:46-48.

27. Wu MD, Cheng MJ, Wang BC, Yech YJ, Lai JT, Kuo YH, Yuan GF, Chen IS. Maleimide and maleic anhydride derivatives from the mycelia of Antrodia camphorata and their nitric oxide inhibitory activities in macrophages. J Nat Prod. 2008; 71:1258-1261.

28. Chien SC, Chen ML, Kuo HT, Tsai YC, Lin BF, Kuo YH. Anti-inflammatory activities of new succinic and maleic derivatives from the fruiting body of Antrodia camphorata. J Agric Food Chem. 2008; 56:7017-7022.

29. Kumar KJS, Vani MG, Chueh PJ, Mau JL, Wang SY. Antrodin C Inhibits epithelial-to-mesenchymal transition and metastasis of breast cancer cells via suppression of smad $2 / 3$ and $\beta$-catenin signaling pathways. PLoS One. 2015; 10:e0117111.

30. He Y, Wang N, Shen Y, Zheng Z, Xu X. Inhibition of high glucose-induced apoptosis by uncoupling protein 2 in human umbilical vein endothelial cells. Int J Mol Med. 2014; 33:1275-1281.

31. Arun P, Aleti V, Parikh K, Manne V, Chilukuri N. Senescence marker protein 30 (SMP30) expression in eukaryotic cells: existence of multiple species and membrane localization. PLoS One. 2011; 6:e16545.

32. Zhang E, Guo Q, Gao H, Xu R, Teng S, Wu Y. Metformin and Resveratrol Inhibited High Glucose-Induced Metabolic Memory of Endothelial Senescence through SIRT1/p300/ p53/p21 Pathway. PLoS One. 2015; 10:e0143814.

33. Stein GH, Drullinger LF, Soulard A, Dulic V. Differential roles for cyclin-dependent kinase inhibitors p21 and p16 in the mechanisms of senescence and differentiation in human fibroblasts. Mol Cell Biol. 1999; 19:2109-2117.

34. Maeda M, Hayashi T, Mizuno N, Hattori Y, Kuzuya M. Intermittent high glucose implements stress-induced senescence in human vascular endothelial cells: role of superoxide production by NADPH oxidase. PLoS One. 2015; 10:e123169.

35. Campisi J. Senescent cells, tumor suppression, and organismal aging: good citizens, bad neighbors. Cell. 2005; 120:513-522.

36. Ben-Porath I, Weinberg RA. The signals and pathways 
activating cellular senescence. Int J Biochem Cell Biol. 2005; 37:961-976.

37. Suzuki E, Takahashi M, Oba S, Nishimatsu H. Oncogeneand oxidative stress-induced cellular senescence shows distinct expression patterns of proinflammatory cytokines in vascular endothelial cells. Sci World J. 2013; 2013:754735.

38. Takahashi A, Ohtani N, Hara E. Irreversibility of cellular senescence: dual roles of $\mathrm{p} 16(\mathrm{INK} 4 \mathrm{a}) / \mathrm{Rb}$-pathway in cell cycle control. Cell Div. 2007; 2:10.

39. Peng C, Ma J, Gao X, Tian P, Li W, Zhang L. High glucose induced oxidative stress and apoptosis in cardiac microvascular endothelial cells are regulated by FoxO3a. PLoS One. 2013; 8:e79739.

40. Candido R, Srivastava P, Cooper ME, Burrell LM. Diabetes mellitus: a cardiovascular disease. Curr Opin Investig Drugs. 2003; 4:1088-1094.

41. Kuo $\mathrm{YH}$, Lin $\mathrm{CH}$, Shih CC. Antidiabetic and antihyperlipidemic properties of a triterpenoid compound, dehydroeburicoic acid, from Antrodia camphorata in vitro and in streptozotocin-induced mice. J Agric Food Chem. 2015; 63:10140-10151.

42. Phuong do T, Ma CM, Hattori M, Jin JS. Inhibitory effects of antrodins A-E from Antrodia camphorata and their metabolites on hepatitis C virus protease. Phytother Res. 2009; 23:582-584.

43. Chen YH, Guh JY, Chuang TD, Chen HC, Chiou SJ, Huang JS, Yang YL, Chuang LY. High glucose decreases endothelial cell proliferation via the extracellular signal regulated kinase/p15(INK4b) pathway. Arch Biochem Biophys. 2007; 465:164-171.

44. Wu QD, Wang JH, Fennessy F, Redmond HP, BouchierHayes D. Taurine prevents high-glucose-induced human vascular endothelial cell apoptosis. Am J Physiol. 1999; 277:C1229-1238.

45. Baumgartner-Parzer SM, Wagner L, Pettermann M, Grillari J, Gessl A, Waldhäusl W. High-Glucose-Triggered Apoptosis in Cultured Endothelial Cells. Diabetes. 1995; 44:1323-1327.

46. Senthil Kumar KJ, Gokila Vani M, Mau JL, Lin CC, Chu FH, Wei CC, Liao VH, Wang SY. A steroid like phytochemical Antcin $M$ is an anti-aging reagent that eliminates hyperglycemia-accelerated premature senescence in dermal fibroblasts by direct activation of $\mathrm{Nrf} 2$ and SIRT-1. Oncotarget. 2016; 7:62836-62861. https://doi. org/10.18632/oncotarget.11229

47. Wang C, Youle RJ. The Role of Mitochondria in Apoptosis*. Ann Rev Genetic. 2009; 43:95-118.

48. Ho FM, Liu SH, Liau CS, Huang PJ, Lin-Shiau SY. High Glucose-Induced Apoptosis in Human Endothelial Cells Is Mediated by Sequential Activations of c-Jun NH2-Terminal Kinase and Caspase-3. Circulation. 2000; 101:2618-2624.

49. Garcia Soriano F, Virag L, Jagtap P, Szabo E, Mabley JG, Liaudet L, Marton A, Hoyt DG, Murthy KGK, Salzman AL,
Southan GJ, Szabo C. Diabetic endothelial dysfunction: the role of poly(ADP-ribose) polymerase activation. Nat Med. 2001; 7:108-113.

50. Burton DGA. Cellular senescence, ageing and disease. Age. 2009; 31:1-9.

51. Lee BY, Han JA, Im JS, Morrone A, Johung K, Goodwin EC, Kleijer WJ, DiMaio D, Hwang ES. Senescenceassociated $\beta$-galactosidase is lysosomal $\beta$-galactosidase. Aging Cell. 2006; 5:187-195.

52. Zhong W, Zou G, Gu J, Zhang J. L-arginine attenuates high glucose-accelerated senescence in human umbilical vein endothelial cells. Diabet Res Clin Pract. 2010; 89:38-45.

53. Servillo L, D’Onofrio N, Longobardi L, Sirangelo I, Giovane A, Cautela D, Castaldo D, Giordano A, Balestrieri ML. Stachydrine ameliorates high-glucose induced endothelial cell senescence and SIRT1 downregulation. J Cell Biochem. 2013; 114:2522-2530.

54. D’Onofrio N, Servillo L, Giovane A, Casale R, Vitello M, Marfella R, Paolisso G, Balestrieri ML. Ergothioneine oxidation in the protection against high-glucose induced endothelial senescence: Involvement of SIRT1 and SIRT6. Free Radic Biol Med. 2016; 11: 211-222.

55. Servillo L, D’Onofrio N, Balestrieri ML. Ergothionene antioxidant function: From chemistry to cardiovascular potential. J Cardiovasc Pharmacol. 2017; 69: 183-191.

56. Gokila Vani M, Senthil Kumar KJ, Liao JW, Chien SC, Mau JL, Chiang SS, Lin CC, Kuo YH, Wang SY. Antcin C from Antrodia camphorata protects liver cells against free radical-induced oxidative stress and apoptosis in vitro and in vivo through Nrf2-dependent mechanism. Evid Based Complement Alternat Med. 2013; 2013:17.

57. Chen F, Qian LH, Deng B, Liu ZM, Zhao Y, Le YY. Resveratrol protects vascular endothelial cells from high glucose-induced apoptosis through inhibition of NADPH oxidase activation-driven oxidative stress. CNS Neurosci Ther. 2013; 19:675-681.

58. Masha A, Brocato L, Dinatale S, Mascia C, Biasi F, Martina V. $N$-acetylcysteine is able to reduce the oxidation status and the endothelial activation after a high-glucose content meal in patients with Type 2 diabetes mellitus. J Endocrinol Investig. 2009; 32:352-356.

59. Iori E, Pagnin E, Gallo A, Calo L, Murphy E, Ostuni F, Fadini GP, Avogaro A. Heme oxygenase-1 is an important modulator in limiting glucose-induced apoptosis in human umbilical vein endothelial cells. Life Sci. 2008; 82:383-392.

60. Li H, Wang F, Zhang L, Cao Y, Liu W, Hao J, Liu Q, Duan H. Modulation of Nrf2 expression alters high glucoseinduced oxidative stress and antioxidant gene expression in mouse mesangial cells. Cell Signal. 2011; 23:1625-1632.

61. Wang MX, Ren LM. Growth inhibitory effect and apoptosis induced by extracellular ATP and adenosine on human gastric carcinoma cells: involvement of intracellular uptake of adenosine. Acta Pharmacol Sin. 2006; 27:1085-1092. 